\title{
Soil Water Content Monitoring for Irrigation Management: A Geostatistical Analysis
}

J. Burdette Barker*, Ph.D. Candidate, Biological Systems Engineering Department, University of Nebraska-Lincoln, 14 L.W. Chase Hall, 3605 Fair St., Lincoln, NE 68583-0726. 801-663-1556, burdette.barker@ huskers.unl.edu.

Trenton E. Franz, Ph.D. Assistant Professor, School of Natural Resources, University of Nebraska-Lincoln, and Robert B. Daugherty Water for Food Global Institute Faculty Fellow, 303 Hardin Hall, 3310 Holdrege St., Lincoln, NE 68583-0973. 402-472-8718 Fax: 402-472-2946. tfranz2@unl.edu.

Derek M. Heeren, Ph.D., P.E. Assistant Professor, Biological Systems Engineering Department, University of Nebraska-Lincoln, and Robert B. Daugherty Water for Food Global Institute Faculty Fellow, 241 L.W. Chase Hall, 3605 Fair St., Lincoln, NE 68583-0726. 402-472-8577, Fax 402-472-6338. derek.heeren@ unl.edu.

Christopher M. U. Neale, Ph.D., Director of Research, Robert B. Daugherty Water for Food Global Institute at the University of Nebraska, and Professor, Biological Systems Engineering Department, University of NebraskaLincoln, 2021 Transformation Dr., Suite 3220, Lincoln, NE 68588-6203. 402-472-5359. cneale@ nebraska.edu.

Joe D. Luck, Ph.D., Assistant Professor, Biological Systems Engineering Department, University of NebraskaLincoln, 204 L.W. Chase Hall, 3605 Fair St., Lincoln, NE 68583-0726. 402-472-1488, Fax 402-472-6338. jluck2@unl.edu.

*corresponding author

Keywords (cosmic ray probe, monitoring locations, soil water content, temporal stability, variable rate irrigation)

\begin{abstract}
With the increasing attention to site-specific or variable rate irrigation management, it is helpful to reconsider the quantity and placement of soil water monitoring locations in this context. Volumetric soil water content $\left(\theta_{\mathrm{v}}\right)$ was monitored using a neutron probe (NP) at 72 locations in a center pivot irrigated field in eastern Nebraska. Variance reduction and temporal stability analyses were performed on $\theta_{\mathrm{v}}$ from shallow ( $\sim$ top $\left.46 \mathrm{~cm}\right)$ and full profile $(\sim 122$ $\mathrm{cm}$ ) readings for four monitoring cycles in the 2015 growing season and 2016 preseason. Eleven additional cycles were included for a subset of the data for the temporal stability analysis. The spatial correlation scale for $\theta_{\mathrm{v}}$ was found to be less than the closest spacing of monitoring locations in the study (i.e. $<37 \mathrm{~m}$ ). For this field site,
\end{abstract}

Page 1 of 34

(C) 2017. This manuscript version is made available under the Elsevier user license http://www.elsevier.com/open-access/userlicense/1.0/ 
approximately three neutron probe monitoring locations were required to determine mean soil water depletion $( \pm 2$ $\mathrm{cm})$ for the field or for a management zone. Little economy would be gained in variance reduction for areal mean $\theta_{\mathrm{v}}$ from using a stratified network for management areas of about 17 ha or greater. However, a stratified design would reduce monitoring locations for areas of about 13 ha or less. Temporally stable monitoring locations were identified. However, relatively low cost spatial predictor variables, including elevation, deviation from mean elevation, apparent electrical conductivity, and mean relative difference of interpolated cosmic ray probe surveys, were not consistent predictors of NP mean relative difference. The small range of variability of $\theta_{\mathrm{v}}$ within the study field is thought to be a contributing factor. It is possible that for fields with similar variability or for VRI where zones have been selected to reduce within-zone variance, that sensor quantity is more important than placement in quantifying the areal mean $\theta_{\mathrm{v}}$ for irrigation management.

\section{Introduction}

Soil water measurement is an invaluable tool for irrigation scheduling (Evett, 2007). Recent irrigation management research has highlighted the importance of incorporating soil water into variable rate irrigation (VRI) management models (e.g., O'Shaughnessy et al., 2015; Stone et al., 2015). Traditional soil water techniques provide only point measurements of soil water. Such point measurements may not be representative of a field or sub area of a field if poorly selected. However, the use of dense grids of soil water sensors for irrigation management is impractical from economic, logistical, and data management standpoints. This is a challenge for both conventional irrigation and emerging VRI management.

The question of how many soil water sensors is sufficient to characterize the areal mean soil water content is addressed by Evett et al. (2009). However, their study focused on research plot spatial scales, which are much smaller than many production fields. Tollner et al. (1991) developed a method for determining the number of soil water locations needed to reduce the $95 \%$ confidence interval to within $20 \%$ of their defined range of 10 to $80 \mathrm{kPa}$. They recommend four to six neutron probe monitoring locations in "uniform soils" as being adequate (see also Evett, 2007). Tollner et al. (1991) suggest that field size was not a very significant factor in their analysis. Another approach to examining the number of measurement locations necessary to quantify an areal mean can be borrowed from rainfall network design and analysis (Morrissey et al., 1995; Rodríguez-Iturbe and Mejía, 1974). In such studies, the reduction in the estimate of the variance of the areal mean relative to the point variance resulting from 
monitoring at multiple locations is evaluated. This reduction has been called a variance reduction factor $(V R F)$ (Manfreda and Rodríguez-Iturbe, 2006; Morrissey et al., 1995; Rodríguez-Iturbe and Mejía, 1974). The VRF for single storm events is defined by Rodríguez-Iturbe and Mejía (1974) as: $\sigma_{N}^{2}=V R F\left(\sigma_{p}^{2}\right)$; where $\sigma_{p}^{2}$ is the point variance (the point standard deviation being $\sigma_{p}$ ), calculated from all measurements for a given event and $\sigma_{N}{ }^{2}$ is the variance of the arithmetic mean of the measurements (the corresponding standard deviation being $\sigma_{N}$ ), with the subscript $N$ corresponding to the number of point samples within the area $A$ (see also Manfreda and RodríguezIturbe, 2006). Thus, if the variance associated with making a point measurement is known, the reduction in variance resulting from taking multiple measurements in space can be determined, provided a correlation function is known (Rodríguez-Iturbe and Mejía, 1974). In their analysis, Rodríguez-Iturbe and Mejía (1974) included a simple correlation function which is given with notation following Morrissey et al. (1995) as: $\rho(d)=\exp (-d / h)$; where $\rho(d)$ is the correlation for two points at a distance, $d$, apart, and $h$ is the "e-folding distance" (Rodríguez-Iturbe and Mejía, 1974). The VRF method was developed by Rodríguez-Iturbe and Mejía (1974) as a means of calculating the tradeoff between the number of monitoring locations and accuracy of the resulting measured areal mean. This same methodology can be used to optimize the number of monitoring locations for soil water and other environmental variables at the field or management zone level, if a suitable correlation function is identified.

If the number of monitoring locations necessary to quantify the areal mean soil water can be identified using VRF methods, then the question of where soil water should be monitored still remains. It may be possible to identify monitoring networks that improve upon stratified or random sensor placement as was examined by Rodríguez-Iturbe and Mejía (1974). Temporal stability analysis is a common method employed to identify spatially representative areas (Evett, 2007; Vachaud et al., 1985; Wang et al., 2015). Temporal stability analysis involves analyzing measurements from many spatially distributed soil water sites in relation to the spatial mean over time. Temporally stable locations may be defined as those that remain relatively consistent in rank relative to other locations in time (Vachaud et al., 1985). The temporally stable locations, particularly those that closely approximate the aerial mean, may be used as representative monitoring locations. Thus, temporal stability analysis may be used as a tool for objectively locating representative areas of a field for soil water monitoring (Guber et al., 2008; Kaleita et al., 2007; Li and Shao, 2014; Starr, 2005). Employing temporal stability represents a possible improvement over what is likely a more subjective process. 
Both temporal stability and $V R F$ analyses require relatively spatially intensive soil water measurements. This requirement makes such analyses impractical outside of research. One possible alternative is the inclusion of ancillary datasets including elevation maps and apparent electrical conductivity surveys. Numerous studies have considered relating temporal stability analysis with other spatial variables (Vanderlinden et al., 2012). In their review of temporal stability studies, Vanderlinden et al. (2012) concluded that temporal stability is affected by multiple factors and that methods for identifying temporally stable monitoring locations need to be further developed. Additional spatial datasets that, as far as we are aware in published literature, have not been examined for this purpose include cosmic-ray neutron probe (CRP) surveys (Dong et al., 2014; Franz et al., 2015; Zreda et al., 2012).

CRPs function by measuring counts of incoming fast cosmic neutrons near the land surface. As fast neutrons are slowed down (or thermalized) most effectively by collisions with hydrogen, there is an inverse relationship with $\theta_{\mathrm{v}}$ (in contrast to the positive relationship typical of conventional neutron moisture gauges). CRPs are estimated to have a footprint radius on the order of 130 to 300 m (Desilets and Zreda, 2013; Köhli et al., 2015). CPRs are sensitive to a depth typically less than $30 \mathrm{~cm}$, being dependent on soil water content and other factors (Franz et al., 2012; Köhli et al., 2015). The CRP footprint is notably large relative to the potential size of water management zones within an agricultural field. However, approximately $63 \%$ of the CRP measured response is typically from radius of about 50 to $150 \mathrm{~m}$ from the probe (Desilets and Zreda, 2013; Köhli et al., 2015). Furthermore, if CRP measurements are collected at a fine enough spatial resolution, it may be possible to generate gridded soil water maps that provide insight into spatial soil water patterns. This can be accomplished using a mobile CRP unit, or rover, such as that described by Chrisman and Zreda (2013). CRP rovers have been shown to be effective at mapping soil water at a scale of $1 \mathrm{~km}$ (Franz et al., 2015). CRP rover surveys represent a method of producing spatial soil estimates of the upper root zone that may be feasible for an agricultural service provider.

Spatial maps of $\theta_{v}$ from CRP surveys could be produced for input into a temporal stability analysis to improve point soil water monitoring network design. Chrisman and Zreda (2013) used a form of temporal stability analysis on interpolated CRP surveys in the Tucson Basin of Arizona. They then used the spatial pattern of variability in soil water from the CRP surveys to model spatial soil water in time using a stationary CRP. This study, however, did not compare the temporal stability analysis from the CRP with point $\theta_{\mathrm{v}}$ measurements. We are unaware of any studies 
that have attempted to employ temporal stability on CRP surveys to approximate temporally stable point monitoring locations. CRPs have recently been used to estimate field scale root zone soil water products from an exponential filter (Peterson et al., 2016) and help close the water balance with corresponding eddy covariance towers (SchreinerMcGraw et al., 2016). The study presented here will continue to investigate the utility of CRPs in providing pragmatic and effective water management strategies in agricultural settings.

The primary objective of the present study was to identify the optimal number and placement of soil water monitoring locations for irrigation management, with consideration of VRI management. A secondary objective was to identify a method for identifying the optimal placement of soil monitoring locations within management units. To this end, temporal stability and $V R F$ analyses were performed on a grid of soil water data, which were part of a field experiment in eastern Nebraska in 2015 and the preseason of 2016. Temporal stability was performed on collected CRP rover maps of the study field.

\section{Materials and Methods}

\subsection{Research Site}

The research site for the study was a production center pivot irrigated field at the University of Nebraska's Agricultural Research and Development Center near Mead, Nebraska. The field is approximately 53 ha in total and is planted half to maize and half to soybeans in an annual rotation. The current research was during the 2015 growing season and preseason of 2016 in the northern approximately 25 ha half of the field, which was planted to Maize in 2015. The field was managed under conservation tillage practices with controlled wheel traffic, the only tillage operation being anhydrous ammonia injection prior to maize planting.

The field is dominated by Yutan silty clay loam, Tomek, Filbert, and Fillmore silt loam soil series, all having loess parent material (Soil Survey Staff, 2013). The Yutan and Tomek are more prevalent and are present in the upslope areas with the Filbert dominating in the low areas and the Fillmore, a hydric soil, being present in local depressions and poorly drained areas (Soil Survey Staff, 2013). The Agricultural Research and Development Center is located within the Todd Valley of Saunders County, Nebraska, an abandoned river valley. Consequently, the area is known to have spatially varying soils, including sandbars within the loess derivative soils. No sand bars have been observed in the study field. 
Normal 1981-2010 annual precipitation at the nearby Mead 6S Global Historical Climatology Network site was 747 mm with 487 mm for May through September NCEI (n.d.-a). In 2015, the totals were about $1073 \mathrm{~mm}$ annual and $738 \mathrm{~mm}$ for May through September, for the same station (NCEI, n.d.-b). The total May through September 2015 ASCE Standardized tall reference ET (ET $\mathrm{rs}_{\mathrm{rs}}$; ASCE-EWRI, 2005) in the vicinity was computed to be $713 \mathrm{~mm}$ as compared with $883 \mathrm{~mm}$ on average from 1995 to 2014 . $\mathrm{ET}_{\mathrm{rs}}$ was computed using weather data from the Mead Agronomy Farm weather station of the High Plains Regional Climate Center's Automated Weather Data Network.

\subsection{Soil water Measurements}

Seventy-two access tubes were installed in the north half of the field following emergence of the maize crop in 2015. The tubes were installed as part of an irrigation research study (data not presented here). Figure 1 is a map of the access tube layout. Locations of the tubes were identified with a combination of GPS and tape measure. The precision of location coordinates was estimated to be approximately $\pm 4 \mathrm{~m}$ in the row direction and $\pm 1 \mathrm{~m}$ in the direction perpendicular to rows. Soil water readings were taken using a 503 ELITE Hydroprobe neutron moisture gauge (Instrotek, Inc., Raleigh, North Carolina). Neutron probe (NP) readings were taken using 30-second counts with standard counts taken prior to the first and after the last soil water counts each day. The average of the two standard counts was used for calculating the count ratios for each day. Neutron counts were taken at six measurement depths centered at approximately 15, 30, 46, 76, 107, and $137 \mathrm{~cm}$ below ground surface. A depth control stand, constructed after Evett et al. (2003), was used to provide a more consistent depth of readings from location to location so that readings were not affected by the height of the access tube above the ground surface.

The NP was calibrated for volumetric soil water content $\left(\theta_{\mathrm{v}}\right)$ using 30 soil samples collected during the installation of the access tubes in May 2015. An additional 34 calibration samples from a nearby plot study were also included in the calibration, as were 17 samples collected in the south half of the study field in August 2015 in an attempt to obtain drier calibration samples. Of these 17 samples, one was thrown out of the calibration because it was a very clear outlier and, therefore, the recorded wet sample mass was considered suspect. The soil samples were obtained from soil cores collected with a direct push soil sampler (Giddings Machine Company, Windsor, Colorado). A single core was taken for each calibration point with NP readings being taken in the sample hole after core collection. The moisture content range of the samples was approximately 0.25 to about $0.45 \mathrm{~m}^{3} \mathrm{~m}^{-3}$; however only one sample of all 80 included samples was less than $0.30 \mathrm{~m}^{3} \mathrm{~m}^{-3}$. While this is a notably wet range, it matched well 
the range observed for the routine NP measurements during the study and was therefore deemed adequate. The calibration regression analysis was performed using the $\mathrm{lm}$ function in R. A single calibration equation was used for all depths as the slope for the $15 \mathrm{~cm}$ depth was not found to be significantly different than that of the deeper depths at the five percent significance level. The coefficient of determination $\left(\mathrm{R}^{2}\right)$ for the final calibration was 0.78 . The RMSE of measured vs. predicted $\theta_{\mathrm{v}}$ using the calibration was computed (using Microsoft Excel) to be $0.016 \mathrm{~m}^{3} \mathrm{~m}^{-3}$.

Soil water measurements were taken approximately weekly for the period from June 24 through October 8, 2015, and another round of readings was taken on May 6, 2016, prior to planting of that year's crop. The neutron access tubes were divided into two geographic regions, with 42 in the east and 30 in the west. Readings generally took two days to complete with the east locations being read first and then the west ones being read the following day. The exception was the May 6, 2016 reading, wherein all locations were measured in a single day. Readings were typically taken in the morning to early afternoon. The two-day readings did cause the west half of the field to have slightly lower $\theta_{\mathrm{v}}$ on average than the east half, but the difference was deemed negligible for the current study. Table 1 is a list of NP measurement dates included in this study. Occasionally, light rainfall fell between readings, e.g. late afternoon or evening of the first day or early morning of the second. These events are noted in Table 1 . These events were assumed to be negligible as they were often of less magnitude than the daily $\mathrm{ET}_{\mathrm{rs}}$, which averaged about 4.7 $\mathrm{mm} \mathrm{d}^{-1}$ between May and September 2015.

Soil water data from two depth ranges were included in the analysis. The included $\theta_{\mathrm{v}}$ were: 1 ) the average of the two shallow readings, $15 \mathrm{~cm}$ and $30 \mathrm{~cm}\left(\theta_{\mathrm{vs}}\right)$, and 2$)$ a $122-\mathrm{cm}$ profile weighted average $\left(\theta_{\mathrm{vp}}\right)$. The $\theta_{\mathrm{vp}}$ was taken to represent the approximated managed root zone and was calculated as:

$$
\theta_{v p}=\frac{0.75 \theta_{v 15}+0.5 \theta_{v 30}+0.75 \theta_{v 46}+\theta_{v 76}+\theta_{v 107}}{4}
$$

where the numerical subscripts are the measurement depths in $\mathrm{cm}$ and it was assumed that the $107 \mathrm{~cm}$ reading represented a depth down to $122 \mathrm{~cm}$.

In addition to the NP measurements, nine CRP surveys were taken concurrent with the NP measurements during the study (Table 1). Of these nine, only four were included in the final analysis because of the possible confounding influence of the irrigation study. The four included surveys are indicated in Table 1. Although four is a relatively small subset of the total dataset, Guber et al. (2008) suggested that one month of data was sufficient to characterize 
temporal stability. They also found that measurement intervals did not affect their temporal stability results up to a weekly frequency. However, they acknowledged that this may not be applicable outside of their study location. They also noted that this finding may be specific to their study site and found that the duration of the study does affect the temporal stability analysis. They also cite, for example, Martínez-Fernández and Ceballos (2005), who found that one year of measurements was adequate to characterize locations with temporally stable soil water.

All CRP surveys, except the May 6, 2016 one, were taken using a backpack mounted CRP rover. Backpack CRP survey protocol was to take 12-minute neutron counts near about two-thirds of the NP locations. Readings were taken near NP access tubes at the ends of east-west rows and approximately every other NP location in between. Care was taken to maintain a minimal separation distance of about 35 to $60 \mathrm{~m}$ between the NP and the CRP to reduce noise in the CRP data. For the May 6, 2016 survey, a pickup-mounted CRP rover was used as the crop had not yet been planted. The pickup-mounted CRP survey included one-minute counts. CRP position for each reading was obtained from a WASS GPS integrated in the system. CRP surveys were interpolated to a 10-m grid using inverse distance weighting after applying a "drop-in-the-bucket" smoothing (Serreze et al., 2003). The smoothing and interpolation were performed using MATLAB (The Mathworks, Inc., Natick, Massachusetts). All neutron data were processed and converted to $\theta_{\mathrm{v}}$ following standard protocols in crop areas (see Franz et al., 2015, for details). The interpolated grid followed the UTM Zone $14 \mathrm{~N}$ orientation. Note that the NP access tubes were installed in eastwest running rows that were oriented roughly two degrees north of east from the UTM grid. The analysis was limited to points within the half circle directly under the center pivot. This extraction was performed using ArcGIS 10.4 (Esri, Redlands, California) and MATLAB. This resulted in a grid of 2268 points that were included in the analysis.

\subsection{Variance Reduction Factor}

The NP data for the four dates indicated in Table 1, for all 72 NP locations, were used to analyze the spatial correlation of the soil water measurements. The correlation function (see Section 1) fit was examined with regard to spatial correlation of the NP data for each of the four dates. This examination included both $\theta_{\mathrm{vs}}$ and $\theta_{\mathrm{vp}}$, separately. The $V R F$ was determined following Rodríguez-Iturbe and Mejía (1974) for a single event assuming a stratified network design; however, it will be shown that the results hold for a random network design also. To fit the correlation function, separation distances $(d)$ were calculated between each NP location and all other NP locations 
within the field without duplication. The separation pairings were then divided into $8 \mathrm{~m}$ bins starting at $0 \mathrm{~m}$ and being inclusive of the upper bound. The first bin with a nonzero count was $32 \mathrm{~m}<d \leq 40 \mathrm{~m}$. The midpoint $d$ for each bin was used as the representative $d$ for fitting and plotting (36 m, $44 \mathrm{~m}$, and so on). Only bins with a pair count of 10 or greater were included in the analysis. The most distant bin meeting this criterion was centered at $584 \mathrm{~m}$. For fitting purposes, $\rho(d)$ was set to unity at $d=0 \mathrm{~m}$, because at zero separation distance, NP locations would be paired with themselves and would have $\rho=1$.

\subsection{Temporal Stability Analysis}

TS analysis was performed in the same manner as Wang et al. (2015) by calculating relative difference (RD) of soil water for each NP location in relation to the arithmetic mean of all readings for a given date. This RD is similar to the $\delta$ defined by Vachaud et al. (1985), but here was calculated using $\theta_{\mathrm{v}}$. The mean relative difference (MRD) and standard deviation of the relative difference (SDRD) for each NP location over the course of several readings were calculated in attempt to identify temporally stable locations for $\theta_{\mathrm{vs}}$ and $\theta_{\mathrm{vp}}$ within the field. It is noted that there is some bias in the NP data because access tubes were not placed in areas known to be prone to early season flooding. An approximately $80 \mathrm{~m}$ swath running north and south through the north half of the field, which is the site of a former rail line was also avoided. Access tubes were also not placed in the vicinity of a pipeline that runs east and west across the northern end of the study area. This is not expected to explicitly introduce bias.

The temporal stability was run for all plots up through the July 22, 2015 readings and also including May 6, 2016 (the four measurements listed in Table 1). After July 22, 2015, experimental irrigation treatments were applied to the field that precluded running temporal stability analysis for the entire NP dataset as a whole after that time. These treatments are not presented here. A second analysis was thus performed for only 18 of the NP locations, which were irrigated similarly throughout the season, and 17 that were rainfed throughout the study. The intended total gross irrigation for the irrigated locations was about $46 \mathrm{~mm}$ total for the 2015 season. At the end of the season, a bank of four malfunctioning sprinklers was identified on the center pivot. It is unknown when the electronic control for those sprinklers began to malfunction or what the impact may have been to soil water in those locations. The effect was considered random error and was perhaps not atypical of a production setting. It was assumed that by May 6, 2016, all experimental effects had been washed out by accumulated precipitation. 
Our purpose was to identify a predictor, or set of predictor variables, that was relatively inexpensive to obtain to identify temporally stable monitoring locations within the field. Therefore, a similar temporal stability analysis was performed for interpolated CRP surveys from the same four measurement periods as were included for all $72 \mathrm{NP}$ locations. The intent of this analysis was to determine whether similar areas of the field were found to be temporally stable from the CRP and NP datasets. To this end, gridded $\theta_{\mathrm{vs}}$ and $\theta_{\mathrm{vp}}$ datasets were also produced from the NP data in a manner similar to the CRP interpolations. Temporal stability analysis was similarly performed on these datasets for comparison. MRD, SDRD, and rankings for all datasets were computed using Microsoft Excel.

Three other spatial datasets were also considered for correlation with the computed MRD values. These datasets included: elevation (Z), deviation from mean elevation (DEV; De Reu et al., 2013) and apparent electrical conductivity $\left(\mathrm{EC}_{\mathrm{a}}\right)$. Elevation was obtained from the Nebraska Department of Natural Resources 2-m LIDAR data archive (Nebraska Department of Natural Resources, 2011). The 2-m digital elevation model (DEM) was aggregated to a $10-\mathrm{m}$ grid aligned with the interpolated $\theta_{\mathrm{v}}$ datasets using ArcGIS. DEV is similar to the topographic index (De Reu et al., 2013; Mieza et al., 2016) and has been shown by De Reu et al. (2013) to be more effective at identifying topographic features. DEV was selected as a useful index for the study field because the soil morphology and hydrology are affected by small scale surface features like depressions, local maxima, and drainage ways. DEV was computed from the $10 \mathrm{~m}$ DEM just described. Four different search radii were explored in computing DEV: 40, 80, 120 , and $160 \mathrm{~m}$. The $120 \mathrm{~m}$ radius was selected for the final analysis based on having the best overall correlation with other parameters in preliminary examination. $\mathrm{EC}_{\mathrm{a}}$ was obtained from a survey with a Veris MSP (Veris Technologies, Salina, Kansas) taken on Nov. 12, 2014. The deep range (90\% response between 0 and $90 \mathrm{~cm}$ below ground surface) $\mathrm{EC}_{\mathrm{a}}$ was used for the current study. The $\mathrm{EC}_{\mathrm{a}}$ was interpolated using inverse distance weighting with a search radius of $21 \mathrm{~m}$ and a weighting exponent of 2, using ArcGIS. The $\mathrm{EC}_{\mathrm{a}}$ was interpolated to the same $10 \mathrm{~m}$ grid as the other spatial datasets. The correlation between the MRD and the various spatial datasets was computed as were multiple linear regression coefficients for prediction of MRD. Correlations were computed using the Hmisc package (Harrell, 2016) in R (R Development Core Team). Regression analysis was performed in Microsoft Excel. 


\section{Results and Discussion}

\subsection{Variance Reduction and Required Number of Monitoring Sites}

The calculated correlations for $\theta_{\mathrm{vs}}$ and $\theta_{\mathrm{vp}}$ are plotted in Figure 2 versus distance. It is clear that $h$, is likely smaller than the spacing of the NP access tubes in this study. The closest NP spacings were approximately $37 \mathrm{~m}$, which is within the distance bin centered at $36 \mathrm{~m}$. Western et al. (2004) cite a review by Western et al. (1998), in which, the variogram correlation lengths for $\theta_{\mathrm{v}}$ were in the range of 1 to $600 \mathrm{~m}$, with many in the 20 to $300 \mathrm{~m}$ range. In their own study, Western et al. (2004) found that the correlation length varied temporally at four New Zealand locations. The resulting lengths ranged from 14 to $330 \mathrm{~m}$, with Western et al. (2004) summarizing that typical values were 30 to $60 \mathrm{~m}$. Thus, it is expected that $h$ is smaller or similar in scale to the closest spacings of NP in the current experiment. Thus an $h$ of approximately $20 \mathrm{~m}$ is not an unreasonable assumption, considering the data and that $h$ could be much smaller. The correlation functions plotted in Figure 2 are for $h=20 \mathrm{~m}$. Considering denser spacing than in this plot study is unreasonable for production agriculture. So, it is sufficient to demonstrate that $h$ is likely on the same order of magnitude as in other studies.

Rodríguez-Iturbe and Mejía (1974) demonstrate that the $V R F$ is a function of the non-dimensional parameter $A h^{-2}$ (following our notation), where $A$ is the area over which measurements are taken, and $h$, which is essentially the correlation length, was defined in Section 1. We shall assume that $h$ is on the order of $20 \mathrm{~m}$ and that the correlation function presented in Section 1 is valid. For a 50 ha irrigated field $\left(A=50,000 \mathrm{~m}^{2}\right)$, the $V R F$ is not notably less than $1 / N$, with $N$ being the number of soil water measurement locations within $A$ for $N<26$ for a randomly placed network (Rodríguez-Iturbe and Mejía, 1974). There are some economies in network design beginning at about $N>6$ for a stratified network design, however. There is further economy gained, particularly for a stratified network design for smaller than field scale management units. Haghverdi et al. (2015), found that four to five sub-field scale management areas or zones were an adequate number to account for much of the variability in available water capacity for two center pivot irrigated fields in Tennessee. This being the case, a typical management zone for a quarter-section center pivot irrigated field (about 50 ha) would be 10 ha or larger (though a management zone may not be contiguous). For areas of this size, a stratified network would result in reduced $N$ for $N>3$, while a random network would not result in appreciably less than $1 / N$ for $N<7$.

Page 11 of 34 
Calculated areal $\theta_{\mathrm{v}}$ sample means for both the $\theta_{\mathrm{vs}}$ and $\theta_{\mathrm{vp}}\left(\theta_{\mathrm{vs}}\right.$ and $\theta_{\mathrm{vp}}$, respectively) and $\sigma_{p}$ for the four included NP survey dates are presented in Table 2 . As expected, $\theta_{\mathrm{vp}}$ values are all greater than the corresponding values for $\theta_{\mathrm{vs}}$. Likewise, $\sigma_{p}$ values are less for the $\theta_{\mathrm{vp}}$ than for the $\theta_{\mathrm{vs}}$ values. This reduction is expected because of the effect of averaging multiple readings in the profile and the expectation that $\theta_{v}$ in the subsoil will be generally more uniform than near the surface (Guber et al., 2008; Li and Shao, 2014; Wang et al., 2016; Wang et al., 2015). Because of the amount of precipitation in the region, it is generally expected that the soil profile will reach field capacity or wetter during the off season. Therefore, it is expected that lower depths will also have greater $\theta_{\mathrm{v}}$ than the shallower depths. Assuming a 122-cm managed root zone, with an available water capacity of 0.17 for the Yutan and Tomek soil series (Fillmore is 0.18 and Filbert is 0.15) (Soil Survey Staff, 2016), the total root zone available water may be approximately $20.7 \mathrm{~cm}$. This is rather typical of a silt loam or silty clay loam (Martin et al., 1990). If a management allowable depletion of $50 \%$ is assumed, then up to about $10.4 \mathrm{~cm}$ of water could be depleted before an irrigation would be necessary. A producer may reasonably desire to know the areal average water depletion below field capacity within about $\pm 2 \mathrm{~cm}$. In a 122 -cm root zone, this is equivalent to a $\theta_{\mathrm{vp}}$ within $\pm 0.016 \mathrm{~m}^{3} \mathrm{~m}^{-3}$. If approximately $95 \%$ confidence is desired, then the desired $\sigma_{N}$ is about $0.016 \mathrm{~m}^{3} \mathrm{~m}^{-3} / 1.96$, or $0.0082 \mathrm{~m}^{3} \mathrm{~m}^{-3}$. The resulting desired $\sigma_{N}^{2}$ would then be about $0.000067 \mathrm{~m}^{6} \mathrm{~m}^{-6}$. Using a typical $\sigma_{p}$ from Table 2 for the profile average of about $0.013 \mathrm{~m}^{3} \mathrm{~m}^{-3}$, corresponding to a $\sigma_{p}^{2}$ of $0.000169 \mathrm{~m}^{6} \mathrm{~m}^{-6}$, this would require a $V R F$ of 0.41 . (Note we estimate that $\sigma_{p}$ would only increase to about $0.017 \mathrm{~m}^{3} \mathrm{~m}^{-3}$ if we reduce the number of NP locations down to as few as 20.) Table 3 is a summary of calculated minimum $\mathrm{N}$ required per management unit to achieve a $V R F$ of 0.41 for a 50-ha square field divided in to one to five management units. Both stratified and random network designs are considered. From Table 3 it is observed that about three neutron probe monitoring locations would be adequate per management zone for three or fewer zones. These locations could be either placed randomly or stratified. For four or five management units, $N$ could be reduced to two, if a stratified design is implemented. These computed number of locations result from the assumed short correlation length and the large areas typical in production fields (as discussed earlier).

The number of monitoring locations in Table 3 are consistent with the recommendation of three to four locations made by Evett (2007) citing Tollner et al. (1991). They are, however, larger than the single NP site calculated by Evett et al. (2009) as being adequate to determine $\theta_{\mathrm{v}}$ for a 100 -cm profile within $\pm 1 \mathrm{~cm}$ at the $90 \%$ level. The 
difference being chiefly that the $\sigma_{p}$ in the current study was more than double that reported by Evett et al. (2009). The larger $\sigma_{p}$ is likely due to the much greater size of area in the current study, with correspondingly greater probability of increased spatial variability in soil properties, soil surface crop residue, crop conditions, and landforms. Vereecken et al. (2014) cite literature recommending 3 to 35 measurement locations as being necessary to quantify $\theta_{\mathrm{v}}$ within $2 \%$ at the $95 \%$ confidence level. Using that same criteria would result in nine locations using the data from our experiment, which fits nicely within the cited range. It is noted that other locations that demonstrate greater variability would require additional monitoring locations. If VRI management is practiced, then the required number of monitoring locations would be 3 for each management zone, for a total of 9 to 12 total locations within a field. Thus it can be shown that, depending on the soil water monitoring technology used, managing irrigation based solely on adequate soil water monitoring could become cost prohibitive and producers are likely to settle, possibly unknowingly, for greater uncertainty.

The results presented here may be conservative as they represent the wet end of the $\theta_{\mathrm{v}}$ range for this field and approach. It has been demonstrated that variance decreases in drier soils and is greatest in the transition from dry to wet (Famiglietti et al., 2008; Vereecken et al., 2014; Vereecken et al., 2007). Vereecken et al. (2007) found that variance peaked at $\theta_{\mathrm{v}}$ closer to $0.2 \mathrm{~m}^{3} \mathrm{~m}^{-3}$ for silt loam and silty clay loam soils. It is therefore possible that $\sigma_{p}$ would be greater in a dry year than the values presented in Table 2 . However, for conditions that we have observed in this field, we feel this analysis is representative. Caution should be exercised in applying the values in this paper to other soil water monitoring technologies. The variance values used in this discussion are based on NP measurements; other technologies are likely to result in greater $\sigma_{p}$ (Evett et al., 2009) and, thus, greater $N$ to achieve similar $V R F$. The increase may be on the order of 2 to 72 times more monitoring locations as summarized by Evett et al. (2009) for their plots. Thus, it is clear that it is impractical in row crop production irrigation management to adequately monitor soil water using some sensor technologies. This has particular importance for VRI management. It is feasible to envision three to possibly a dozen soil water monitoring sites within a field, but two dozen or 100 would likely be economically and logistically unreasonable for practitioners. We therefore assert that while multiple studies have demonstrated the necessity of incorporating soil water monitoring into VRI management (O'Shaughnessy et al., 2015; Stone et al., 2015), soil water measurement alone will likely be impractical to achieve necessary precision to justify site-specific management. Rather, we affirm that VRI management will necessitate a combination of soil 
water monitoring and modeling in the absence of low cost, reliable, and pragmatic sensors, dataloggers, and telemetry for real-time monitoring alone.

\subsection{Temporal Stability}

Plots of ranked MRD for the 72 NP locations for the four monitoring events noted in Table 1 are found in Figure 3. The included irrigated treatment and rainfed treatment plots are noted in Figure 3 for reference with the longer term MRD calculations. It is immediately apparent that the range of MRD is relatively small ( $\pm 10 \%$ for both $\theta_{\mathrm{vs}}$ and $\theta_{\mathrm{vp}}$ ) as compared with other studies. For example, Wang et al. (2015) report MRD values on the order of $\pm 40 \%$ for native grasslands in the Nebraska sand hills. Li and Shao (2014) observed a similar range in their study in irrigated agriculture in northwestern China. In our study, we arbitrarily defined temporally stable locations, which some have taken to be MRD near zero (Vachaud et al., 1985; Wang et al., 2015), as $-1 \%<$ MRD < 1\%. This range represents approximately the inner $25 \%$ of readings, though the distributions (particularly for $\theta_{\mathrm{vp}}$ ) are not quite symmetrical. The temporally stable locations for $\theta_{\mathrm{vs}}$ were not necessarily the same as for $\theta_{\mathrm{vp}}$. This is not uncommon in the literature (e.g. Guber et al., 2008; Li and Shao, 2014). However, some areas of the field are temporally stable for both depth ranges.

The temporally stable locations occur in various slope conditions but, with a few exceptions, not in local extrema. There were five NP locations --22, 25, 28, 42 and 65-- that were temporally stable for both depth ranges under this criterion. In other cases, it is adjacent NP locations that are temporally stable for one depth and the neighbor for the other. Locations 25, 28, and 42 were on a side slope, with 25 being high and 28 low on the same slope and 42 low on a different slope. Locations 22 and 65 are in local valleys, though typically upslope of areas, which visually appear to be subject to standing water for extended periods after large rainfall events.

Two of the five NP locations that were defined as temporally stable for both $\theta_{\mathrm{vs}}$ and $\theta_{\mathrm{vp}}$ were also found to be temporally stable, under the same criterion for the full 15-measurement cycle analysis on the irrigated treatment. These locations, 42 and 65, were also the only two of these five locations that were included in either of the 15measurement analyses. Figure 4 contains plots of MRD rankings for the full season temporal stability analysis of the irrigated and rainfed treatments for both $\theta_{\mathrm{vs}}$ and $\theta_{\mathrm{vp}}$. The ranges in MRD in Figure 4 are similar to those presented in Figure 3 for all 72 locations and only four early season measurements. The number of locations that met the criterion of $-1 \%<\mathrm{MRD}<1 \%$ was similar for the irrigated treatment as in the 72 location analysis, being roughly

Page 14 of 34 
the inner third of the rankings (though again the distributions are not quite symmetrical, which is not unexpected for only 18 observations). There were two other irrigated locations that were temporally stable for both $\theta_{\mathrm{vs}}$ and $\theta_{\mathrm{vp}}$ (locations 57 and 59), which were near each other. The rainfed treatment, on the other hand, had only four locations that met the temporally stable criterion for $\theta_{\mathrm{vp}}$ and only one for $\theta_{\mathrm{vs}}$. This one location (no. 18) for $\theta_{\mathrm{vs}}$ was also a temporally stable location for $\theta_{v s}$ in the 72 location analysis. There were no rainfed locations that were temporally stable for both $\theta_{\mathrm{vs}}$ and $\theta_{\mathrm{vp}}$. This may be related more to the fact that the rainfed locations were possibly not in as temporally stable locations to begin with based on the 72 location analysis, rather than the non-irrigated condition of those locations.

One objective of this study was to explore the possibility of identifying temporally stable soil water monitoring locations based on CRP surveys and other spatial variables. Therefore, temporal stability analysis was performed on the afore mentioned gridded CRP surveys and gridded NP datasets for the same four monitoring cycles as were used in the temporal stability analysis of the 72 locations. The ranked MRD values for the CRP surveys are presented in Figure 5. One thing is apparent: While the range in MRD is somewhat greater than was observed for the point NP temporal stability analyses, the computed SDRD values for the CRP are considerably greater, roughly four times greater on average than for the $\theta_{\mathrm{vs}}$ analysis for all 72 locations for the same measurements surveys. This may seem counter intuitive, because of the larger footprint of the CRP and the smoothing effect of interpolation, but upon further examination, it is reasonable. The CRP had much lower neutron counts than the NP. While the NP, even at shallow depths, recorded thousands of neutrons in each 30-sec reading, the CRP may have recorded a few hundred over a 12-minute interval. The CRP is also most sensitive to the very upper layers of soil, which the NP $\theta_{\mathrm{vs}}$ is less sensitive to because of the depth of measurements and the averaging of the $15-\mathrm{cm}$ and $30-\mathrm{cm}$ readings. We expect that the surface soil water detected by the CRP rovers is more variable than even the $\theta_{\mathrm{vs}}$ from the NP just as $\theta_{\mathrm{vs}}$ was found to be less variable than $\theta_{\mathrm{vp}}$ and as discussed in 3.1. A possible avenue for research would be applying a soil profile $\theta \mathrm{v}$ estimate --for example. an exponential filter (Peterson et al., 2016)-- to extend CRP survey depth as a means of predicting temporal stability locations for deeper soil water monitoring. It is noted that while we assume that the growing crop and surface crop residue in the study field was rather uniform, these variables may improve sensor placement prediction (see Baroni et al., 2013; Wang et al., 2015). 
A visual comparison between the MRD and SDRD results and NP locations can be accomplished using the results in Figures $3-5$ and the gridded data values for the CRP presented in Figure 6. For further comparison between the CRP and NP data, MRD and SDRD images for the gridded $\theta_{\mathrm{vs}}$ and $\theta_{\mathrm{vp}}$ values are also presented in Figure 6.

Visually, there are similar patterns between the CRP MRD and the MRD maps for the NP data, but correlation does not appear very clear. The patterns in SDRD are also quite different for the different gridded datasets. Elevation, $\mathrm{DEV}$, and $\mathrm{EC}_{\mathrm{a}}$ maps are also presented in Figure 6 for visual comparison. Again, visual comparison with these spatial variables and the computed MRD values does not immediately appear very clear.

Correlation analysis was run as described in 2.2, on MRD from the CRP and gridded NP data, elevation, DEV, and $\mathrm{EC}_{\mathrm{a}}$ with each other. Similar analysis was performed for the MRD values from the 72 NP location analysis and the spatial variables, including CRP MRD, extracted to the $72 \mathrm{NP}$ locations. The correlation matrices are presented in Table 4 for both of these correlation analyses. Several correlations were found to be significant when tested at the $5 \%$ level. Notably these include MRD for $\theta_{\mathrm{vs}}$ and $\theta_{\mathrm{vp}}$ for both gridded and NP location analyses; both of these also had significant, though not necessarily strong, correlations with DEV. $\mathrm{EC}_{\mathrm{a}}$ was significantly correlated with MRD from $\theta_{\mathrm{vs}}$ and elevation was found to be significantly correlated with MRD for both gridded $\theta_{\mathrm{vs}}$ and $\theta_{\mathrm{vp}}$. The correlations for the three ancillary spatial datasets with each other were all found to be significant.

A similar correlation analysis was performed by extracting the CRP MRD and the three ancillary spatial variables to the 18 irrigated and 17 rainfed locations and comparing with the 15-measurement MRD values. The resulting correlation matrices are presented in Table 5. Also included in this analysis were MRD values computed for the 18 irrigated and 17 rainfed NP locations for only the four measurement cycles included in the 72 location and CRP analyses. These allow for time scaling, to see correlation between temporal stability analysis with the limited dataset of four surveys and the more complete 15-survey dataset. MRDs for both $\theta_{\mathrm{vs}}$ and $\theta_{\mathrm{vp}}$ were found to have significant and relatively high correlations ( 0.70 and 0.84 , respectively) between the four-occasion and 15 -occasion analyses for the irrigated plots and similarly for the rainfed plots ( 0.90 for $\theta_{\mathrm{vs}}$ and 0.81 for $\left.\theta_{\mathrm{vp}}\right)$. The correlation between the temporal stability analysis with four surveys and the one with 15 is important because it is evidence that temporally stable locations in a field or management zone could be determined with a few early surveys rather than an intensive season long campaign as suggested by Guber et al. (2008). 
The correlations between MRD for $\theta_{\mathrm{vs}}$ and $\theta_{\mathrm{vp}}$ were not found to be significant at the $5 \%$ level for either the irrigated or rainfed plots regardless of the number of occasions included in the analysis. This result is in contrast with the results for the gridded analysis and the 72 locations and is likely influenced by sample size. The correlation between the MRD for $\theta_{\mathrm{vs}}$ and $\mathrm{EC}_{\mathrm{a}}$ was found to be significant for both irrigated and rainfed plots, but only for the fouroccasion analysis. The rainfed plot $\theta_{\mathrm{vs}}$ also correlated well (0.55) with DEV. The MRD for $\theta_{\mathrm{vp}}$ in the irrigated plots was found to have significant correlations with DEV and CRP MRD, but again only for the four-occasion analysis. The $\theta_{\mathrm{vs}}$ MRD for the 15 surveys correlated well with DEV and $\mathrm{EC}_{\mathrm{a}}$ as the $\theta_{\mathrm{vs}} \mathrm{MRD}$ had for the 72 location analysis in Table 5. Again all ancillary variables had correlations with each other that were found to be significant with the exception of elevation and $\mathrm{EC}_{\mathrm{a}}$ for the irrigated locations.

From Tables 4 and 5, it is apparent that no single ancillary variable, including CRP MRD, stands out as a candidate for a single predictor of MRD for the shallow root zone or full managed profile. However, $\mathrm{EC}_{\mathrm{a}}$ may be the exception for the shallow zone. This is likely because about 50\% of the response of the Veris MSP, for the deep range used herein, is estimated to be within about the top $38 \mathrm{~cm}$ of the soil profile using the response function presented by Sudduth et al. (2005) who cite Roy and Apparao (1971). Thus if characterizing $\theta_{\mathrm{v}}$ in the top soil is of most interest, then $\mathrm{EC}_{\mathrm{a}}$ may be an adequate predictor of optimal soil water monitoring locations for the study field. To further investigate the use of combinations of variables to determine monitoring locations, multiple linear regression analysis was performed between MRD for $\theta_{\mathrm{vs}}$ and $\theta_{\mathrm{vp}}$ and the CRP MRD and three other ancillary variables. This was done for the four-occasion analysis for the 72 locations and both 15-occasion analyses. The regression analysis was also performed using only spatial variables that were found to have correlations with the MRD that were significant at the 5\% level. In this analysis we did not account for blocking that was part of plot study, because we are not interested in treatment effects here.

Results from these regression analyses are presented in Table 6. In general, the prediction of the regression models was poor for the 72-location analyses, with $\mathrm{R}^{2}$ being no greater than 0.28 for $\theta_{\mathrm{vs}} \mathrm{MRD}$ and as low as 0.08 for $\theta_{\mathrm{vs}}$. Better prediction was generally achieved for the 15 -occasion analyses, with $\mathrm{R}^{2}$ reaching 0.77 for the combination of all four predictor variables and $\theta_{\mathrm{vp}}$ MRD for the irrigated locations. Conversely, the $\mathrm{R}^{2}$ was only 0.15 for the same analysis with the rainfed locations. In general, the inclusion of all four predictor variables did not greatly improve the coefficient of determination over the inclusion of only those variables with statistically significant correlations. 
The exceptions are those MRD sets that did not have significant correlations with any of the four predictor variables. Some of the poor fit of these models could be caused by MRD not fully accounting for the variability in $\theta_{\mathrm{v}}$. Starr (2005) performed temporal stability analysis on potato and barley fields in Maine. He demonstrated that a temporal stability model could account for nearly half of the observed variability in soil water measurements in his study. He also reported that, according to the model, random error also accounted for about one fifth of the total variability. Kaleita et al. (2007) similarly found that MRD accounted for approximately half of the variability in their observations on a small field in Illinois.

It may also be possible that there are other predictor variables that would provide better insight than those considered here. For example, repeated $\mathrm{EC}_{\mathrm{a}}$ mapping as done by Pedrera-Parrilla et al. (2016), who collected EC data in an olive orchard in Spain under wet and dry $\theta_{\mathrm{v}}$ conditions. They found that spatial patterns in $\mathrm{EC}_{\mathrm{a}} \mathrm{were}$ similar under both conditions, while under wet conditions $\mathrm{EC}_{\mathrm{a}}$ was generally of a greater magnitude than under dry conditions. They found the difference in $\theta_{\mathrm{v}}$ to be well correlated with the difference in $\mathrm{EC}_{\mathrm{a}}$ under these conditions and suggested mapping $\mathrm{EC}_{\mathrm{a}}$ at multiple times to determine $\theta_{\mathrm{v}}$ patterns. Principle component analysis or empirical orthogonal function analysis (Vanderlinden et al., 2012; Vereecken et al., 2014) may also be an effective means of combining multiple spatial datasets to predict locations for soil water measurement.

The primary advantage of having standardized all variables prior to regression analysis is the ability to treat the regression coefficients as weighting factors showing the importance of one variable over another. Similarly, having standardized the MRD values, regression coefficients were compared among the different analyses. In comparing the regression coefficients, it is found that most commonly $\mathrm{EC}_{\mathrm{a}}$ is the strongest predictor of MRD; although it is not necessarily a strong predictor by itself as may be observed in the correlation matrices in Tables 3 and 4 . It is also noted that in some cases DEV is the strongest predictor. Baroni et al. (2013) found that spatial variability in both soil texture and vegetation impacted soil water variability. They found the prior to be more impactful in wet conditions and vegetation to be so in drier conditions. Wang et al. (2015) also found vegetation to have a greater impact on soil water under dry conditions. This illustrates the potential difficulty of identifying temporally stable locations from other datasets. In our study, conditions could generally be considered wet, which may have some bearing on why $\mathrm{EC}_{\mathrm{a}}$ was correlated with shallow MRD.

Page 18 of 34 
In our study, no clear spatial variable or set of spatial variables was consistent at being a reasonable predictor of MRD and subsequently temporally sable locations for monitoring soil water. Two inferences can be made from this information. First, that the spatial variability in $\theta_{\mathrm{v}}$ is simply not large enough in this field to produce strong relationships with other variables. Second, if this is the case, and if irrigation management zones are designated to minimize variability within each zone, then it may be difficult in a number of cases to identify temporally stable locations within a management zone using proxy variables. This may not be as much of a hindrance to adequate soil water monitoring as may be apparent. In some cases, if management zones are appropriately designated, then soil water monitoring sites may be adequately identified simply by random or stratified placement as discussed in 3.1 . Furthermore, if multiple monitoring locations are necessary to approximate the areal mean $\theta_{\mathrm{v}}$, then the need to intentionally select temporally stable locations is reduced.

This approach of monitoring site selection may be more practical for producers and service providers and is in harmony with the recommendations of Evett (2007). One caveat is that the VRF analysis presented in 3.1 was based on the full NP dataset. That analysis did not account for possible $V R F$ resulting from placing monitoring locations in areas expected to be representative of the areal mean. In such a case, the number of monitoring locations needed to

characterize the mean may be reduced. A final observation is that the data used in the analysis included errors. These errors resulted from data being collected over the course of two days with a clear systematic error in that regard, and some selective placement of NP monitoring locations. These practices were prudent for the plot research and may be similar to practical siting in production irrigation management.

\section{Summary and Conclusions}

The VRF analysis of the 72 NP monitoring locations revealed that spatial correlation scales for $\theta_{\mathrm{v}}$ in the study field are likely smaller than the minimum access tube spacing of approximately $37 \mathrm{~m}$. For this field site, approximately three neutron probe monitoring locations were required to determine mean soil water depletion $( \pm 2 \mathrm{~cm})$ for the field or for a management zone. Considering correlation scales on this magnitude, it is not expected that there is any economy to be gained by strategic monitoring location placement (i.e. random or stratified network designs; Rodríguez-Iturbe and Mejía, 1974). In the context of VRI management, it is apparent that adequate soil water monitoring will be infeasible in many conditions. Rather, we assert that a combination of modeling and soil water

Page 19 of 34 
monitoring will be necessary to achieve sufficient precision for many VRI management objectives. This agrees with findings of others with regards to VRI (e.g. O'Shaughnessy et al., 2015; Stone et al., 2015).

Regarding sensor placement, the temporal stability did help to identify NP locations that were temporally stable, defined as having $|\mathrm{MRD}|<1 \%$. However, the spatial ancillary variables and CRP MRD grid were not consistent predictors of temporally stable monitoring locations at the site. We assume that the study field does not have sufficient variability in $\theta_{v}$ to produce such relationships as have been demonstrated by others (Vanderlinden et al., 2012). We conclude that if adequate soil water monitoring is practiced --i.e., following the VRF analysis herein-then placement may be of lesser importance. This conclusion may possibly hold for fields with a similar amount of variability in $\theta_{\mathrm{v}}$ as the study field here. It may also hold for fields under VRI management, where management zones have been selected to reduce variability sufficiently. This does not eliminate the usefulness of identifying temporally stable monitoring locations, if doing so can reduce the necessary number of monitoring locations to achieve adequate accuracy of measurement with sufficient economy and logistical practicality. Until adequate predictors of temporally stable locations can be identified, temporal stability analysis will remain impractical for production settings.

\section{Acknowledgments}

Mr. Mark Schroder, Director of the ARDC, and his staff, who have been very accommodating for the research. Research support staff and graduate and undergraduate research assistants who helped collect data and without whom, this project would scarcely have been possible. They include: William Avery, Alan Boldt, Ryan Freiberger, Isaiah Krutak, Tsz Him Lo, Rodrigo Dal Sasso Lourenço, Keith Miller, and Matthew Russell. We thank Ms. Ronica Stromberg for her detailed grammatical review of the manuscript. Funding for the project came from the Robert B.

Daugherty Water for Food Global Institute at the University of Nebraska and the Institute of Agriculture and Natural Resources at the University of Nebraska-Lincoln. Barker also received funding from a University of Nebraska Presidential Fellowship. Weather data were provided by the High Plains Regional Climate Center at the University of Nebraska-Lincoln.

Page 20 of 34 


\section{References}

ASCE-EWRI, 2005. ASCE Standardized Reference Evapotranspiration Equation, in: Allen, R.G., Walter, I.A., Elliott, R.L., H., T.A., Itenfisu, D., Jensen, M.E. (Eds.). Environmental and Water Resources Institute of the American Society of Civil Engineers, Reston, VA, p. 216.

Baroni, G., Ortuani, B., Facchi, A., Gandolfi, C., 2013. The role of vegetation and soil properties on the spatiotemporal variability of the surface soil moisture in a maize-cropped field. J. Hydrol. 489, 148-159.

Chrisman, B., Zreda, M., 2013. Quantifying mesoscale soil moisture with the cosmic-ray rover. Hydrology and Earth System Sciences 17, 5097-5108.

De Reu, J., Bourgeois, J., Bats, M., Zwertvaegher, A., Gelorini, V., De Smedt, P., Chu, W., Antrop, M., De Maeyer, P., Finke, P., Van Meirvenne, M., Verniers, J., Crombé, P., 2013. Application of the topographic position index to heterogeneous landscapes. Geomorphology 186, 39-49.

Desilets, D., Zreda, M., 2013. Footprint diameter for a cosmic-ray soil moisture probe: Theory and Monte Carlo simulations. Water Resour. Res. 49, 3566-3575.

Dong, J., Ochsner, T.E., Zreda, M., Cosh, M.H., Zou, C.B., 2014. Calibration and validation of the COSMOS rover for surface soil moisture measurement. Vadose Zone Journal 13.

Evett, S.R., 2007. Soil Water and Monitoring Technology, Irrigation of Agricultural Crops, Agronomy Monograph No. 30, 2 ed. ASA-CSSA-SSSA, Madison, WI, pp. 25-84.

Evett, S.R., Schwartz, R.C., Tolk, J.A., Howell, T.A., 2009. Soil profile water content determination: Spatiotemporal variability of electromagnetic and neutron probe sensors in access tubes. Vadose Zone Journal 8, 926-941.

Evett, S.R., Tolk, J.A., Howell, T.A., 2003. A depth control stand for improved accuracy with the neutron probe. Vadose Zone Journal 2, 642-649.

Famiglietti, J.S., Ryu, D., Berg, A.A., Rodell, M., Jackson, T.J., 2008. Field observations of soil moisture variability across scales. Water Resour. Res. 44, W01423.

Franz, T.E., Wang, T., Avery, W., Finkenbiner, C., Brocca, L., 2015. Combined analysis of soil moisture measurements from roving and fixed cosmic ray neutron probes for multiscale real-time monitoring. Geophysical Research Letters 42, 3389-3396. 
Franz, T.E., Zreda, M., Ferre, T.P.A., Rosolem, R., Zweck, C., Stillman, S., Zeng, X., Shuttleworth, W.J., 2012. Measurement depth of the cosmic ray soil moisture probe affected by hydrogen from various sources. Water Resour. Res. 48, W08515.

Guber, A.K., Gish, T.J., Pachepsky, Y.A., Van Genuchten, M.T., Daughtry, C.S.T., Nicholson, T.J., Cady, R.E., 2008. Temporal stability in soil water content patterns across agricultural fields. Catena 73, 125-133.

Haghverdi, A., Leib, B.G., Washington-Allen, R.A., Ayers, P.D., Buschermohle, M.J., 2015. Perspectives on delineating management zones for variable rate irrigation. Computers and Electronics in Agriculture 117, 154-167.

Harrell, F.E.J., 2016. Hmisc: Harrell Miscellaneous, 3.17-4 ed.

Kaleita, A.L., Hirschi, M.C., Tian, L.F., 2007. Field-scale surface soil moisture patterns and their relationship to topographic indices. Trans. ASABE 50, 557-564.

Köhli, M., Schrön, M., Zreda, M., Schmidt, U., Dietrich, P., Zacharias, S., 2015. Footprint characteristics revised for field-scale soil moisture monitoring with cosmic-ray neutrons. Water Resour. Res. 51, 5772-5790.

Li, D.F., Shao, M.A., 2014. Temporal stability analysis for estimating spatial mean soil water storage and deep percolation in irrigated maize crops. Agricultural Water Management 144, 140-149.

Manfreda, S., Rodríguez-Iturbe, I., 2006. On the spatial and temporal sampling of soil moisture fields. Water Resour. Res. 42, W05409.

Martin, D.L., Stegman, E.C., Fereres, E., 1990. Irrigation Scheduling Principles, in: Hoffman, G.J., Howell, T.A., Solomon, K.H. (Eds.), Management of Farm Irrigation Systems, ASAE Monograph No. 9. American Society of Agricultural Engineers, St. Joseph, MI, pp. 155-203.

Martínez-Fernández, J., Ceballos, A., 2005. Mean soil moisture estimation using temporal stability analysis. J. Hydrol. 312, 28-38.

Mieza, M.S., Cravero, W.R., Kovac, F.D., Bargiano, P.G., 2016. Delineation of site-specific management units for operational applications using the topographic position index in La Pampa, Argentina. Computers and Electronics in Agriculture 127, 158-167.

Morrissey, M.L., Maliekal, J.A., Greene, J.S., Wang, J.M., 1995. The uncertainty of simple spatial averages using rain-gauge networks. Water Resour. Res. 31, 2011-2017. 
NCEI, n.d.-a. Data Tools: 1981-2010 Normals. National Oceanic and Atmospheric Administration National Centers for Environmental Information. http://www.ncdc.noaa.gov/cdo-web/datatools/normals.

NCEI, n.d.-b. Data Tools: Find a Station. National Oceanic and Atmospheric Administration National Centers for Environmental Information. http://www.ncdc.noaa.gov/cdo-web/datatools/findstation.

Nebraska Department of Natural Resources, 2011. NRCS LIDAR DEMs for Eastern Nebraska - 2 meter - 2010, in: Merrick \& Co (Ed.), Aurora, CO.

O'Shaughnessy, S.A., Evett, S.R., Colaizzi, P.D., 2015. Dynamic prescription maps for site-specific variable rate irrigation of cotton. Agricultural Water Management 159, 123-138.

Pedrera-Parrilla, A., Van De Vijver, E., Van Meirvenne, M., Espejo-Pérez, A.J., Giráldez, J.V., Vanderlinden, K., 2016. Apparent electrical conductivity measurements in an olive orchard under wet and dry soil conditions: significance for clay and soil water content mapping. Precision Agriculture 17, 531-545.

Peterson, A.M., Helgason, W.D., Ireson, A.M., 2016. Estimating field-scale root zone soil moisture using the cosmic-ray neutron probe. Hydrol. Earth Syst. Sci. 20, 1373-1385.

Rodríguez-Iturbe, I., Mejía, J.M., 1974. The design of rainfall networks in time and space. Water Resour. Res. 10, 713-728.

Roy, A., Apparao, A., 1971. Depth of investigation in direct current methods. Geophysics 36, 943-959.

Schreiner-McGraw, A.P., Vivoni, E.R., Mascaro, G., Franz, T.E., 2016. Closing the water balance with cosmic-ray soil moisture measurements and assessing their relation to evapotranspiration in two semiarid watersheds. Hydrol. Earth Syst. Sci. 20, 329-345.

Serreze, M.C., Clark, M.P., Bromwich, D.H., 2003. Monitoring precipitation over the arctic terrestrial drainage system: Data requirements, shortcomings, and applications of atmospheric reanalysis. J. Hydrometeorol. 4, $387-407$.

Soil Survey Staff, 2013. Web Soil Survey. U.S. Department of Agriculture Natural Resources Conservation Service. http://websoilsurvey.sc.egov.usda.gov/App/HomePage.htm.

Soil Survey Staff, 2016. Web Soil Survey. U.S. Department of Agriculture Natural Resources Conservation Service. http://websoilsurvey.sc.egov.usda.gov/App/HomePage.htm.

Starr, G.C., 2005. Assessing temporal stability and spatial variability of soil water patterns with implications for precision water management. Agricultural Water Management 72, 223-243.

Page 23 of 34 
Stone, K.C., Bauer, P.J., Busscher, W.J., Millen, J.A., Evans, D.E., Strickland, E.E., 2015. Variable-rate irrigation management using an expert system in the eastern coastal plain. Irrig Sci 33, 167-175.

Sudduth, K.A., Kitchen, N.R., Wiebold, W.J., Batchelor, W.D., Bollero, G.A., Bullock, D.G., Clay, D.E., Palm, H.L., Pierce, F.J., Schuler, R.T., Thelen, K.D., 2005. Relating apparent electrical conductivity to soil properties across the north-central USA. Computers and Electronics in Agriculture 46, 263-283.

Tollner, E.W., Tyson, A.W., Beverly, R.B., 1991. Estimating the number of soil-water measurement stations required for irrigation decisions. Appl. Eng. Agric. 7, 198-204.

Vachaud, G., Passerat de Silans, A., Balabanis, P., Vauclin, M., 1985. Temporal stability of spatially measured soil water probability density function. Soil Sci. Soc. Am. J. 49, 822-828.

Vanderlinden, K., Vereecken, H., Hardelauf, H., Herbst, M., Martinez, G., Cosh, M.H., Pachepsky, Y.A., 2012. Temporal stability of soil water contents: A review of data and analyses. Vadose Zone Journal 11, 19.

Vereecken, H., Huisman, J.A., Pachepsky, Y., Montzka, C., van der Kruk, J., Bogena, H., Weihermuller, L., Herbst, M., Martinez, G., Vanderborght, J., 2014. On the spatio-temporal dynamics of soil moisture at the field scale. J. Hydrol. 516, 76-96.

Vereecken, H., Kamai, T., Harter, T., Kasteel, R., Hopmans, J., Vanderborght, J., 2007. Explaining soil moisture variability as a function of mean soil moisture: A stochastic unsaturated flow perspective. Geophysical Research Letters 34, L22402.

Wang, T., Franz, T.E., Yue, W., Szilagyi, J., Zlotnik, V.A., You, J., Chen, X., Shulski, M.D., Young, A., 2016. Feasibility analysis of using inverse modeling for estimating natural groundwater recharge from a largescale soil moisture monitoring network. J. Hydrol. 533, 250-265.

Wang, T., Wedin, D.A., Franz, T.E., Hiller, J., 2015. Effect of vegetation on the temporal stability of soil moisture in grass-stabilized semi-arid sand dunes. J. Hydrol. 521, 447-459.

Western, A.W., Blöschl, G., Grayson, R.B., 1998. Geostatistical characterisation of soil moisture patterns in the Tarrawarra catchment. J. Hydrol. 205, 20-37.

Western, A.W., Zhou, S.-L., Grayson, R.B., McMahon, T.A., Blöschl, G., Wilson, D.J., 2004. Spatial correlation of soil moisture in small catchments and its relationship to dominant spatial hydrological processes. J. Hydrol. 286, 113-134. 
Zreda, M., Shuttleworth, W.J., Zeng, X., Zweck, C., Desilets, D., Franz, T.E., Rosolem, R., 2012. COSMOS: the COsmic-ray Soil Moisture Observing System. Hydrology and Earth System Sciences 16, 4079-4099. 


\section{Tables}

Table 1. Neutron Probe (NP) and Cosmic Ray Probe (CPR) Measurement Dates Included in the Study.

\begin{tabular}{|c|c|c|c|c|c|c|c|c|}
\hline \multirow[b]{2}{*}{$\begin{array}{c}\text { Reading } \\
\text { No. }\end{array}$} & \multicolumn{3}{|c|}{ East Half $^{\mathbf{1}}$} & \multicolumn{3}{|c|}{ West Half $^{\mathbf{1}}$} & \multirow{2}{*}{$\begin{array}{c}\text { Avg. } \\
\text { ET }_{\text {rs }}^{2} \\
(\mathrm{~mm} / \mathbf{d})\end{array}$} & \multirow{2}{*}{$\begin{array}{c}\text { CRP } \\
\text { Survey }\end{array}$} \\
\hline & Date & $\begin{array}{l}\text { Rain } \\
(\mathrm{mm})\end{array}$ & $\begin{array}{l}\text { Rain } \\
\text { Time }\end{array}$ & Date & $\begin{array}{l}\text { Rain } \\
(\mathbf{m m})\end{array}$ & $\begin{array}{l}\text { Rain } \\
\text { Time }\end{array}$ & & \\
\hline $1^{3}$ & Jun 30 & 2.3 & $\mathrm{PM}$ & Jul 1 & 3.3 & $\mathrm{AM}$ & 3.9 & Backpack \\
\hline $2^{3}$ & Jul 7 & --- & --- & Jul 8 & --- & -- & 5.7 & Backpack \\
\hline $3^{3}$ & Jul 21 & --- & --- & Jul 22 & --- & --- & 5.4 & Backpack \\
\hline 4 & Jul 29 & --- & --- & Jul 30 & --- & --- & 5.7 & Backpack \\
\hline $5^{4}$ & Aug 5 & --- & --- & Aug 6 & 0.3 & AM & 2.6 & Backpack \\
\hline 6 & Aug 11 & --- & --- & Aug 12 & --- & --- & 5.5 & Backpack \\
\hline 7 & Aug 19 & --- & --- & Aug 20 & --- & --- & 5.4 & none \\
\hline 8 & Aug 26 & --- & --- & Aug 27 & 13.5 & PM & 4.5 & Backpack \\
\hline 9 & Aug 31 & --- & --- & Sep 1 & --- & --- & 5.0 & none \\
\hline 10 & Sep 8 & 7.4 & AM & Sep 9 & 3.8 & PM & 3.8 & none \\
\hline 11 & Sep 15 & --- & --- & Sep 16 & --- & --- & 7.1 & Backpack \\
\hline 12 & Sep 21 & --- & --- & Sep 22 & --- & --- & 3.3 & none \\
\hline 13 & Sep 29 & 7.6 & AM & Sep 30 & --- & --- & 4.2 & none \\
\hline 14 & Oct 6 & --- & --- & Oct 7 & --- & --- & 2.8 & none \\
\hline $15^{3}$ & $\begin{array}{c}\text { May 6, } \\
2016\end{array}$ & & & $\begin{array}{c}\text { May 6, } \\
2016\end{array}$ & & & & Pickup \\
\hline
\end{tabular}

1. Soil water was measured on the east half of the study area first and on the west half generally on the following day. NP locations 1-42 were in the east half and 43-72 in the west.

2. Average reference evapotranspiration for the two measurement days. Assuming that the readings are about 24 hrs. apart, this gives an estimate of the evaporative potential during the measurement period. Not included for May 6, 2016 because all readings were taken on one day.

3. Dates included in the final analysis for all 72 NP locations and for CRP surveys. These dates were before irrigation began in 2015 and prior to planting in 2016 .

4. Rainfall on Aug 6 occurred at about 9:50 am and was deemed insignificant.

Table 2. Sample Means and Point Standard Deviations for Shallow and Profile Average Volumetric Water Content $\left(\theta_{\mathrm{vs}}\right.$ and $\theta_{\mathrm{vp}}$, Respectively) for the Four NP Survey Dates Included in the Variance Reduction Analysis.

\begin{tabular}{lccccc}
\hline \multirow{2}{*}{ Date } & \multicolumn{2}{c}{$\boldsymbol{\theta}_{\mathbf{v s}}$} & & \multicolumn{2}{c}{$\boldsymbol{\theta}_{\mathbf{v p}}$} \\
\cline { 2 - 3 } \cline { 5 - 6 } & $\boldsymbol{\theta}_{\mathbf{v s}}\left(\mathbf{m}^{\mathbf{3}} \mathbf{~ m}^{\mathbf{- 3}}\right)^{\mathbf{1}}$ & $\sigma_{p}\left(\mathbf{m}^{\mathbf{3}} \mathbf{~ m}^{\mathbf{- 3}}\right)^{\mathbf{2}}$ & & $\boldsymbol{\theta}_{\mathbf{v p}}\left(\mathbf{m}^{\mathbf{3}} \mathbf{~ m}^{\mathbf{- 3}}\right)$ & $\boldsymbol{\sigma}_{p}\left(\mathbf{m}^{\mathbf{3}} \mathbf{~ m}^{\mathbf{- 3}}\right)$ \\
\hline Jun 30 - Jul 1, 2015 & 0.37 & 0.017 & & 0.39 & 0.012 \\
Jul 7 - Jul 8, 2015 & 0.37 & 0.018 & & 0.38 & 0.013 \\
Jul 21 - Jul 22, 2015 & 0.32 & 0.018 & & 0.35 & 0.013 \\
May 6, 2016 & 0.40 & 0.011 & & 0.40 & 0.010 \\
\hline
\end{tabular}

1. Sample mean.

2. Sample point standard deviation. 
Table 3. Minimum Number of Monitoring Sites for Irrigation Management Zones in a 50 ha Field using Random and Stratified Network Designs Following Rodríguez-Iturbe and Mejía (1974).

\begin{tabular}{|c|c|c|c|c|c|}
\hline \multirow[t]{2}{*}{ No. Zones ${ }^{1}$} & \multirow{2}{*}{$\begin{array}{c}\text { Zone Area } \\
\text { (ha) }\end{array}$} & \multicolumn{2}{|c|}{$\begin{array}{l}\text { Random } \\
\text { Network }\end{array}$} & \multicolumn{2}{|c|}{$\begin{array}{c}\text { Stratified } \\
\text { Network }\end{array}$} \\
\hline & & $\operatorname{Min} N^{2}$ & $V R F^{3}$ & $\operatorname{Min} N$ & VRF \\
\hline 1 & 50.0 & 3 & 0.32 & 3 & 0.30 \\
\hline 2 & 25.0 & 3 & 0.31 & 3 & 0.28 \\
\hline 3 & 16.7 & 3 & 0.30 & 3 & 0.26 \\
\hline 4 & 12.5 & 3 & 0.29 & 2 & 0.40 \\
\hline 5 & 10.0 & 3 & 0.29 & 2 & 0.39 \\
\hline
\end{tabular}

1. Management zones are assumed to be uniform in size.

2. Minimum number of locations needed to obtain a $V R F$ of 0.41 , given $h=20 \mathrm{~m}$.

3 . Variance reduction factor assuming an approximately square monitoring area

(Rodríguez-Iturbe and Mejía 1974).

Table 4. Correlation Matrices for Shallow and Profile Average Volumetric Water Content $\left(\theta_{\mathrm{vs}}\right.$ and $\theta_{\mathrm{vp}}$, Respectively) for All 72 Neutron Probe (NP) Locations and for Interpolated Values with Other Spatial Variables.

\begin{tabular}{|c|c|c|c|c|c|c|}
\hline \multicolumn{7}{|c|}{ All 72 NP Access Tube Locations } \\
\hline & $\begin{array}{c}\boldsymbol{\theta}_{\mathrm{vs}} \\
\mathbf{M R D}_{4}\end{array}$ & $\begin{array}{c}\theta_{\mathrm{vp}} \\
\mathbf{M R D}_{4}\end{array}$ & $\begin{array}{c}\text { CRP }^{\mathbf{i}} \\
\text { MRD }_{4}\end{array}$ & $\mathbf{D E V}^{3}$ & $\mathbf{Z}^{3}$ & $\mathbf{E C}_{\mathbf{a}}{ }^{3}$ \\
\hline$\theta_{\mathrm{vs}} \mathrm{MRD}_{4}{ }^{1}$ & 1 & & & & & \\
\hline$\theta_{\mathrm{vp}} \mathrm{MRD}_{4}{ }^{1}$ & $0.29^{4}$ & 1 & & & & \\
\hline $\mathrm{CRP}^{\mathrm{i}} \mathrm{MRD}_{4}{ }^{1,2}$ & -0.02 & 0.08 & 1 & & & \\
\hline DEV & 0.32 & -0.29 & -0.09 & 1 & & \\
\hline $\mathbf{Z}$ & 0.17 & -0.15 & 0.18 & 0.68 & 1 & \\
\hline $\mathbf{E C}_{\mathbf{a}}$ & 0.52 & -0.13 & -0.08 & 0.62 & 0.31 & 1 \\
\hline
\end{tabular}

All 2251 Gridded Points

\begin{tabular}{|c|c|c|c|c|c|c|}
\hline & $\begin{array}{c}\theta_{\mathrm{vs}}^{\mathrm{i}} \\
\mathbf{M R D}_{4}\end{array}$ & $\begin{array}{c}\boldsymbol{\theta}_{\mathrm{vp}}^{\mathrm{i}} \\
\mathbf{M R D}_{4}\end{array}$ & $\begin{array}{l}\mathrm{CRP}^{\mathrm{i}} \\
\mathrm{MRD}_{4}\end{array}$ & DEV & $\mathbf{Z}$ & $\mathbf{E C}_{\mathbf{a}}$ \\
\hline$\theta_{\mathrm{vs}}^{\mathrm{i}} \mathrm{MRD}_{4}{ }^{2}$ & 1 & & & & & \\
\hline$\theta_{\mathrm{vp}}^{\mathrm{i}^{\mathrm{i}}} \mathrm{MRD}_{4}{ }^{2}$ & 0.62 & 1 & & & & \\
\hline $\mathrm{CRP}^{\mathrm{i}} \mathrm{MRD}_{4}$ & -0.04 & 0.27 & 1 & & & \\
\hline DEV & 0.2 & -0.14 & -0.04 & 1 & & \\
\hline $\mathbf{Z}$ & -0.09 & -0.22 & 0.19 & 0.68 & 1 & \\
\hline $\mathbf{E C}_{\mathbf{a}}$ & 0.17 & 0.01 & -0.03 & 0.63 & 0.4 & 1 \\
\hline
\end{tabular}

1. Mean relative difference, the subscript 4 represents four measurements starting on dates: Jun 30, Jul 7, and Jul 21, 2015 and May 6, 2016.

2. Cosmic ray probe survey, the superscript i represents an interpolated gridded value.

3. DEV is deviation from mean elevation (De Reu et al., 2013), $\mathrm{Z}$ is elevation, and $\mathrm{EC}_{\mathrm{a}}$ is apparent electrical conductivity.

4. Bolded values are significant at the 0.05 level. 
Table 5. Correlation Matrices for Shallow and Profile Average Volumetric Water Content $\left(\theta_{\mathrm{vs}}\right.$ and $\boldsymbol{\theta}_{\mathrm{vp}}$, Respectively) for Irrigated and Rainfed NP Locations with Other Spatial Variables.

\begin{tabular}{|c|c|c|c|c|c|c|c|c|}
\hline \multicolumn{9}{|c|}{18 Irrigation NP Access Tube Locations } \\
\hline & $\begin{array}{c}\boldsymbol{\theta}_{\mathrm{vs}} \\
\text { MRD }_{4} \\
\end{array}$ & $\theta_{\mathrm{vp}} \mathbf{M R D}_{4}$ & $\begin{array}{c}\theta_{\mathrm{vs}} \\
\text { MRD }_{15} \\
\end{array}$ & $\begin{array}{c}\theta_{\mathrm{vp}} \\
\text { MRD }_{15} \\
\end{array}$ & $\begin{array}{c}\mathbf{C R P}^{\mathrm{i}} \\
\mathrm{MRD}_{4} \\
\end{array}$ & $\mathbf{D E V}^{3}$ & $\mathbf{Z}^{3}$ & $\mathbf{E C}_{\mathbf{a}}{ }^{3}$ \\
\hline$\theta_{\mathrm{vs}} \mathrm{MRD}_{4}{ }^{1}$ & 1 & & & & & & & \\
\hline$\theta_{\mathrm{vp}} \mathbf{M R D}_{4}$ & -0.03 & 1 & & & & & & \\
\hline$\theta_{\mathrm{vs}} \mathrm{MRD}_{15}$ & $0.70^{4}$ & 0.08 & 1 & & & & & \\
\hline$\theta_{\mathrm{vp}} \mathrm{MRD}_{15}$ & -0.11 & 0.84 & 0.34 & 1 & & & & \\
\hline $\mathrm{CRP}^{\mathrm{i}} \mathrm{MRD}_{4}{ }^{2}$ & 0.18 & 0.60 & 0.13 & 0.43 & 1 & & & \\
\hline DEV & 0.27 & -0.61 & 0.32 & -0.42 & -0.28 & 1 & & \\
\hline $\mathbf{Z}$ & -0.04 & -0.23 & 0.19 & -0.10 & -0.19 & 0.79 & 1 & \\
\hline $\mathbf{E C}_{\mathbf{a}}$ & 0.67 & -0.29 & 0.33 & -0.37 & -0.05 & 0.58 & 0.20 & 1 \\
\hline \multicolumn{9}{|c|}{17 Rainfed NP Access Tube Locations } \\
\hline & $\begin{array}{c}\boldsymbol{\theta}_{\mathrm{vs}} \\
\mathbf{M R D}_{4}\end{array}$ & $\theta_{\mathrm{vp}} \mathrm{MRD}_{4}$ & $\begin{array}{c}\theta_{\mathrm{vs}} \\
\text { MRD }_{15}\end{array}$ & $\begin{array}{c}\theta_{\mathrm{vp}} \\
\text { MRD }_{15}\end{array}$ & $\begin{array}{l}\mathrm{CRP}^{\mathrm{i}} \\
\mathrm{MRD}_{4}\end{array}$ & DEV & $\mathbf{Z}$ & $\mathbf{E C}_{\mathbf{a}}$ \\
\hline$\theta_{\mathrm{vs}} \mathbf{M R D}_{4}$ & 1 & & & & & & & \\
\hline$\theta_{\mathrm{vp}} \mathrm{MRD}_{4}$ & 0.35 & 1 & & & & & & \\
\hline$\theta_{\mathrm{vs}} \mathrm{MRD}_{15}$ & 0.88 & 0.32 & 1 & & & & & \\
\hline$\theta_{\mathrm{vp}} \mathrm{MRD}_{15}$ & 0.10 & 0.82 & 0.31 & 1 & & & & \\
\hline $\mathbf{C R P}^{\mathrm{i}} \mathbf{M R D}_{4}$ & -0.07 & -0.15 & 0.03 & -0.09 & 1 & & & \\
\hline DEV & 0.59 & 0.01 & 0.51 & -0.11 & 0.02 & 1 & & \\
\hline $\mathbf{Z}$ & 0.19 & -0.09 & 0.12 & -0.18 & 0.3 & 0.69 & 1 & \\
\hline $\mathbf{E C}_{\mathbf{a}}$ & 0.72 & 0.25 & 0.65 & 0.16 & 0.08 & 0.60 & 0.46 & 1 \\
\hline
\end{tabular}

1. Mean relative difference, the subscript 4 represents four measurements starting on dates: Jun 30, Jul 7, and Jul 21, 2015 and May 6, 2016. The subscript 15 represents all 15 measurement dates in Table 1.

2. Cosmic ray probe survey with the superscript i representing an interpolated gridded value.

3. DEV is deviation from mean elevation (De Reu et al., 2013), $\mathrm{Z}$ is elevation, and $\mathrm{EC}_{\mathrm{a}}$ is apparent electrical conductivity.

4. Bolded values were significant at the 0.05 level. 
Table 6. Multiple Linear Regression Coefficients for Shallow and Profile Average Volumetric Water Content $\left(\theta_{\mathrm{vs}}\right.$ and $\theta_{\mathrm{vp}}$, Respectively) with Four Standardized Predictor Variables.

\begin{tabular}{|c|c|c|c|c|c|c|}
\hline \multirow{2}{*}{$\begin{array}{l}\text { NP Tubes } \\
\text { Included }\end{array}$} & \multirow{2}{*}{$\begin{array}{c}\text { Predicted } \\
\text { Variable }\end{array}$} & \multicolumn{4}{|c|}{ Regression Coefficients $^{1}$} & \multirow{2}{*}{$\mathbf{R}^{2}$} \\
\hline & & $\mathrm{CRP}^{\mathrm{i}} \mathrm{MRD}_{4}{ }^{2}$ & DEV & $\mathbf{Z}$ & $\mathbf{E C}_{\mathrm{a}}$ & \\
\hline \multirow[t]{4}{*}{ All 72} & $\theta_{\mathrm{vs}} \mathrm{MRD}_{4}$ & 0.022 & -0.021 & 0.011 & 0.536 & 0.28 \\
\hline & & & -0.014 & & 0.533 & 0.28 \\
\hline & $\theta_{\mathrm{vp}} \mathrm{MRD}_{4}$ & 0.036 & -0.404 & 0.085 & 0.102 & 0.09 \\
\hline & & & -0.287 & & & 0.08 \\
\hline \multirow[t]{2}{*}{18 Irrigated } & $\theta_{\mathrm{vs}} \mathrm{MRD}_{15}$ & 0.220 & 0.370 & -0.092 & 0.143 & 0.18 \\
\hline & $\theta_{\mathrm{vp}} \mathrm{MRD}_{15}$ & 0.389 & -1.402 & 0.879 & 0.358 & 0.77 \\
\hline \multirow[t]{3}{*}{17 Rainfed } & $\theta_{\mathrm{vs}} \mathrm{MRD}_{15}$ & 0.009 & 0.544 & -0.455 & 0.595 & 0.66 \\
\hline & & & 0.250 & & 0.564 & 0.55 \\
\hline & $\theta_{\mathrm{vp}} \mathrm{MRD}_{15}$ & -0.142 & -0.136 & -0.142 & 0.411 & 0.14 \\
\hline
\end{tabular}

1. As regression analyses were performed on standardized variables all calculated intercepts were zero. 2. CRP is cosmic ray probe survey. MRD is mean relative difference. The superscript i represents gridded interpolated value, subscripts 4 and 15 represent four and 15 measurements included, respectively. The four measurements were started on Jun 30, Jul 7 and 21, 2015, and May 6, 2016. The 15 measurements are all 15 from Table 1 . 


\section{Figures}

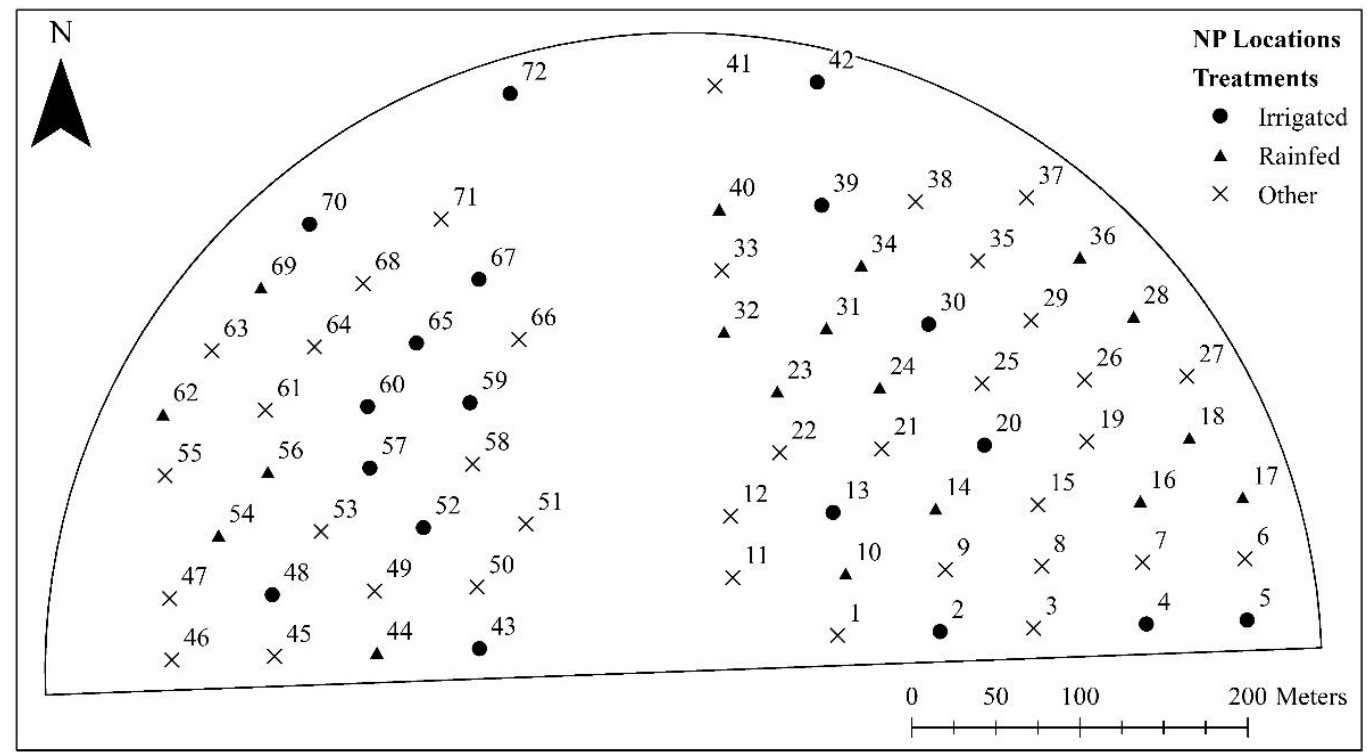

Figure 1. Layout of NP access tubes in the experiment field. Numbers are IDs of tubes, locations marked as “other" are treatments not presented here. 


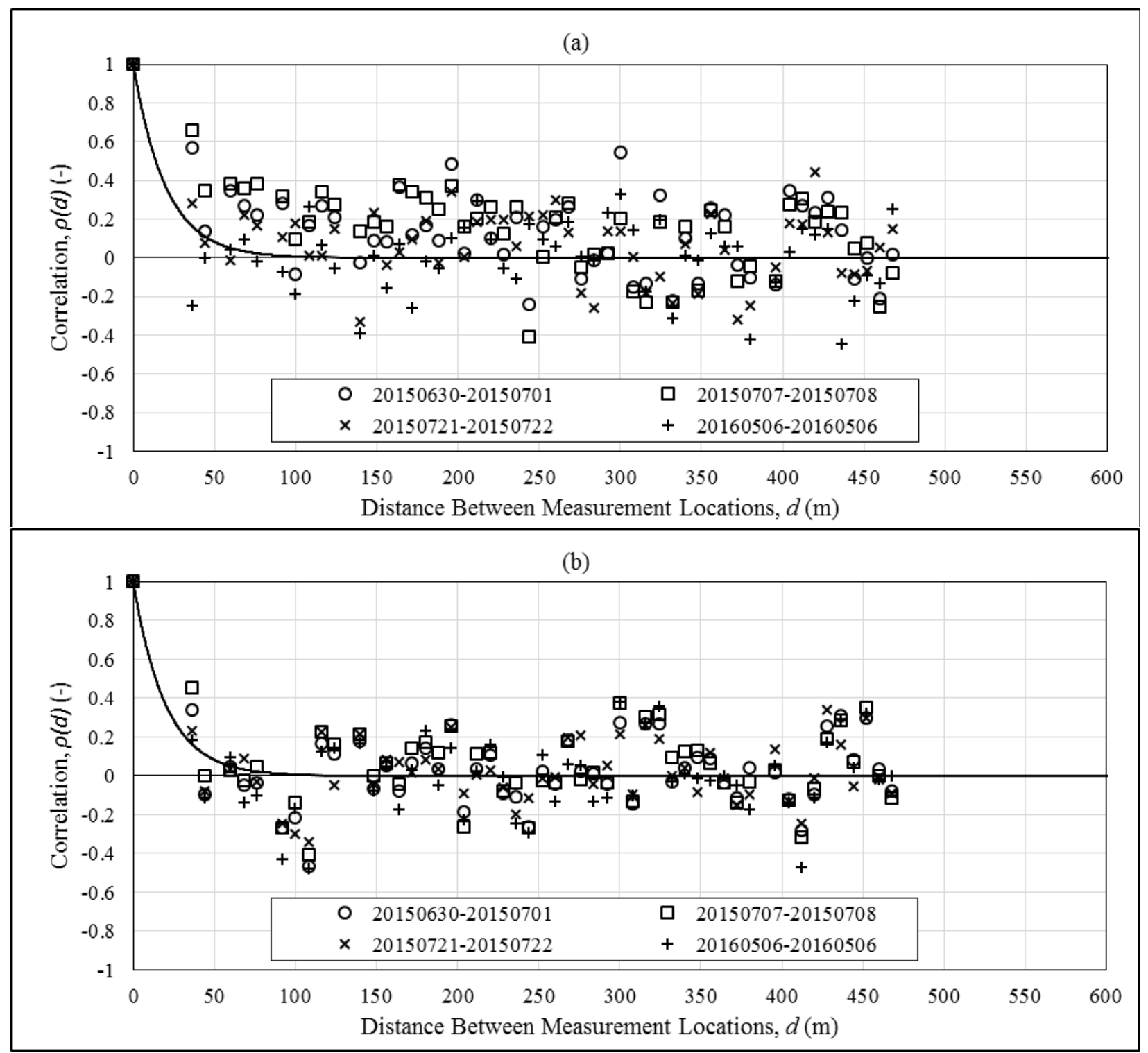

Figure 2. Calculated correlation vs. distance bin for (a) shallow volumetric water content ( $\left.\theta_{\mathrm{vs}}\right)$ and (b) profile average volumetric water content $\left(\theta_{\mathrm{vp}}\right)$ with exponential correlation function for the e-folding distance, $h=20 \mathrm{~m}$ as the solid line. This figure includes only bins for which 10 or more pairings were made. 


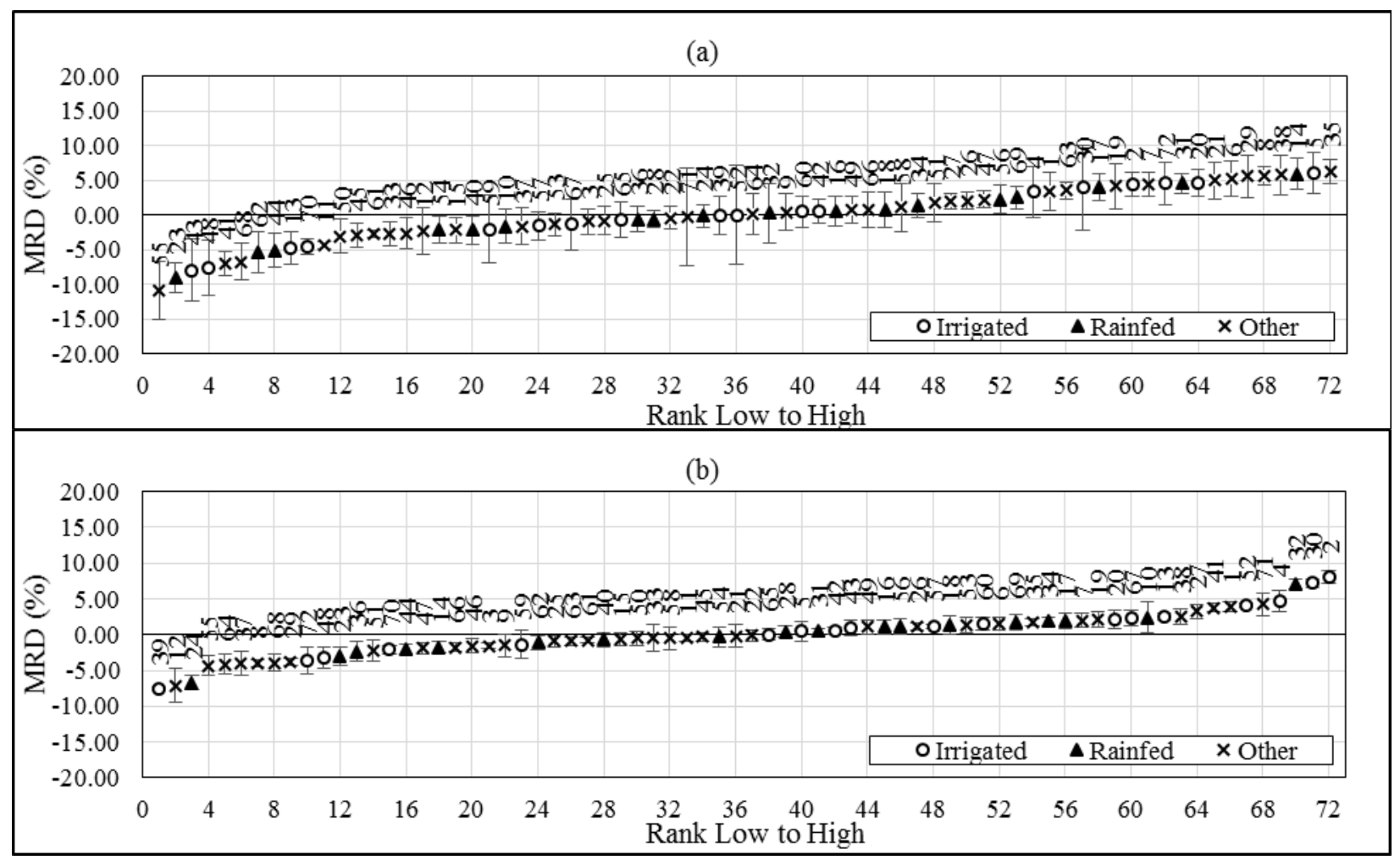

Figure 3. Mean relative difference (MRD) ranking for (a) shallow volumetric water content $\left(\theta_{\mathrm{vs}}\right)$ and (b) profile average volumetric water content $\left(\theta_{\mathrm{vp}}\right)$ for all 72 neutron probe locations for Jun $30-\mathrm{Jul} 1$, Jul 7 - 8, Jul $21-22$, 2015, and May 6, 2016 readings. Error bars are \pm 1 standard deviation of relative difference (SDRD). 


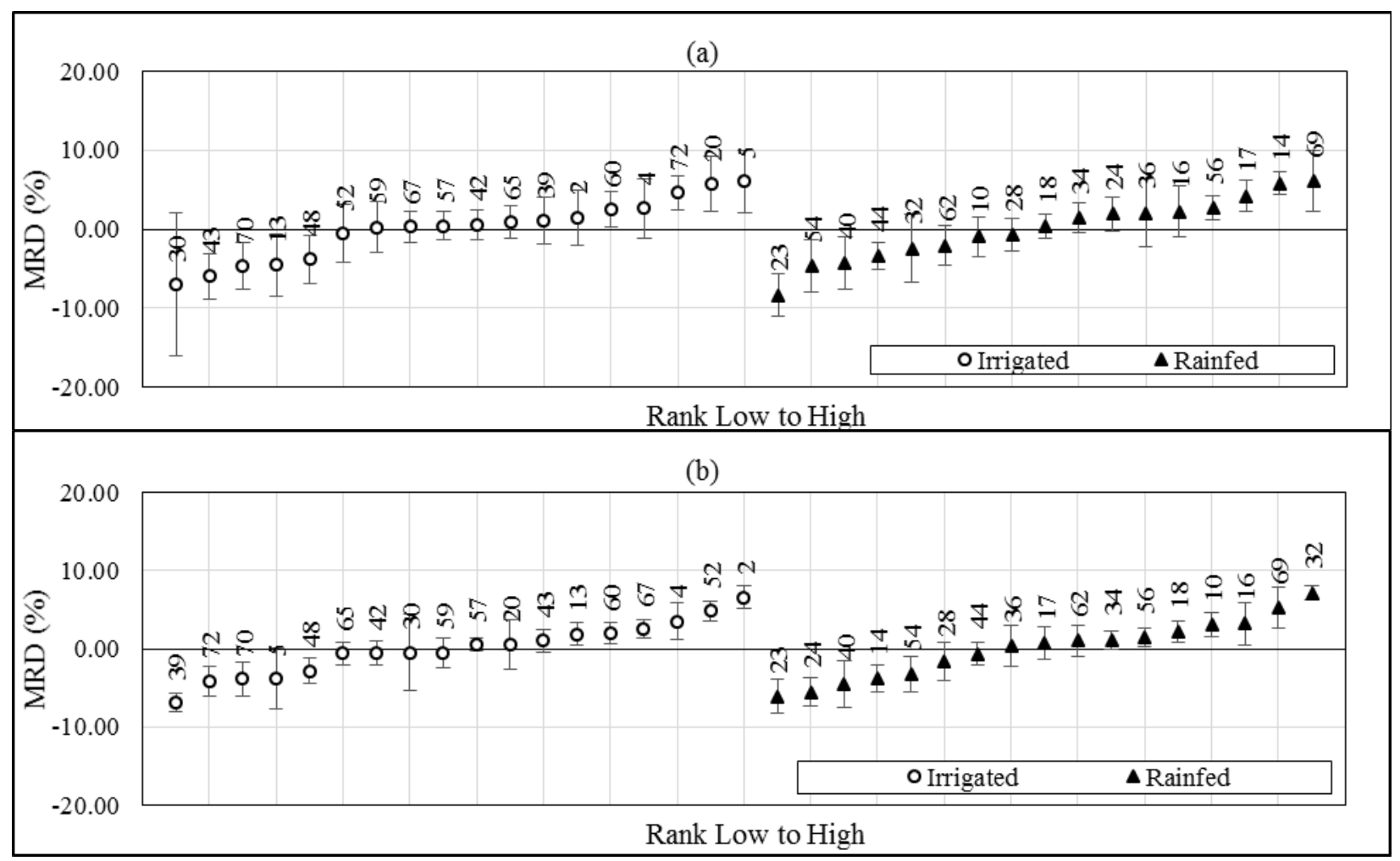

Figure 4. Mean relative difference (MRD) ranking for (a) shallow volumetric water content $\left(\theta_{\mathrm{vs}}\right)$ and (b) profile average volumetric water content $\left(\theta_{\mathrm{vp}}\right)$ for the included irrigated and rainfed treatments for all neutron probe measurement dates presented in Table 1. Error bars are \pm 1 standard deviation of relative difference (SDRD).

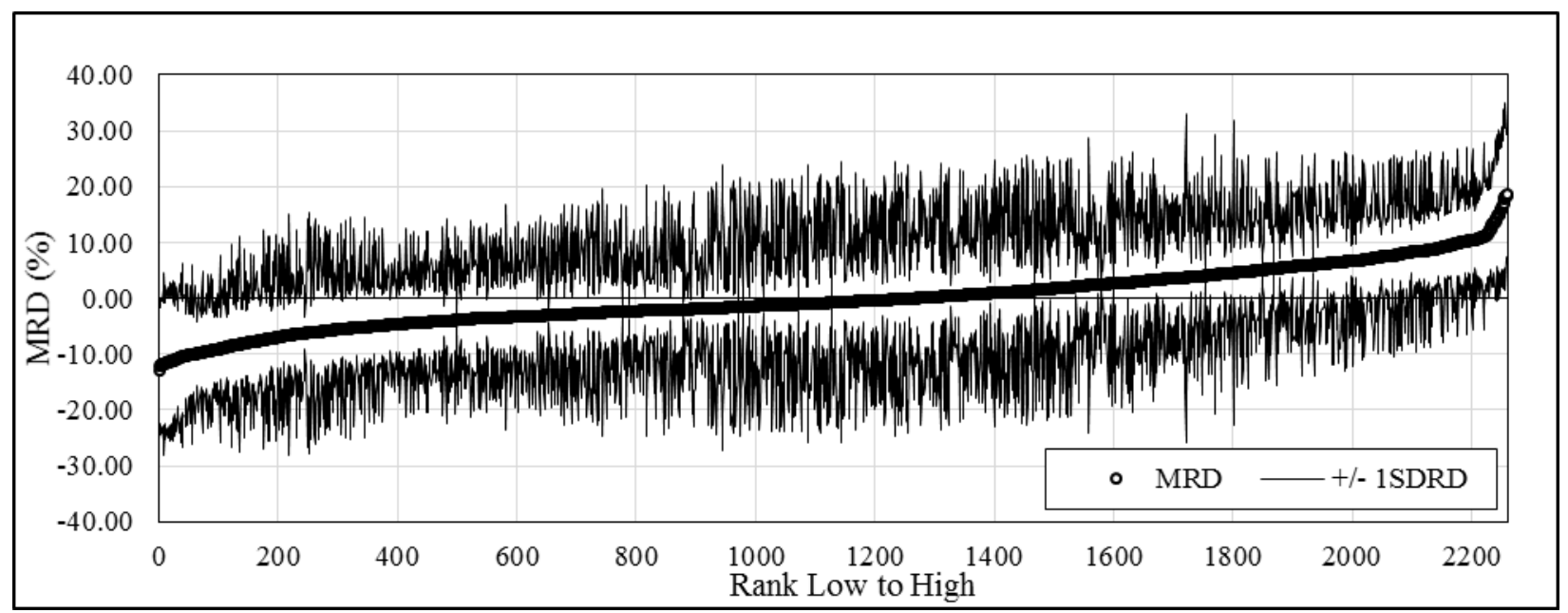

Figure 5. Mean relative difference (MRD) ranking for the cosmic ray probe rover surveys for Jun 30 - Jul 1, Jul 7 8, Jul $21-22$, 2015, and May 6, 2016 readings. SDRD is standard deviation of relative difference. The analysis included a total of 2268 kriged volumetric water content points. 


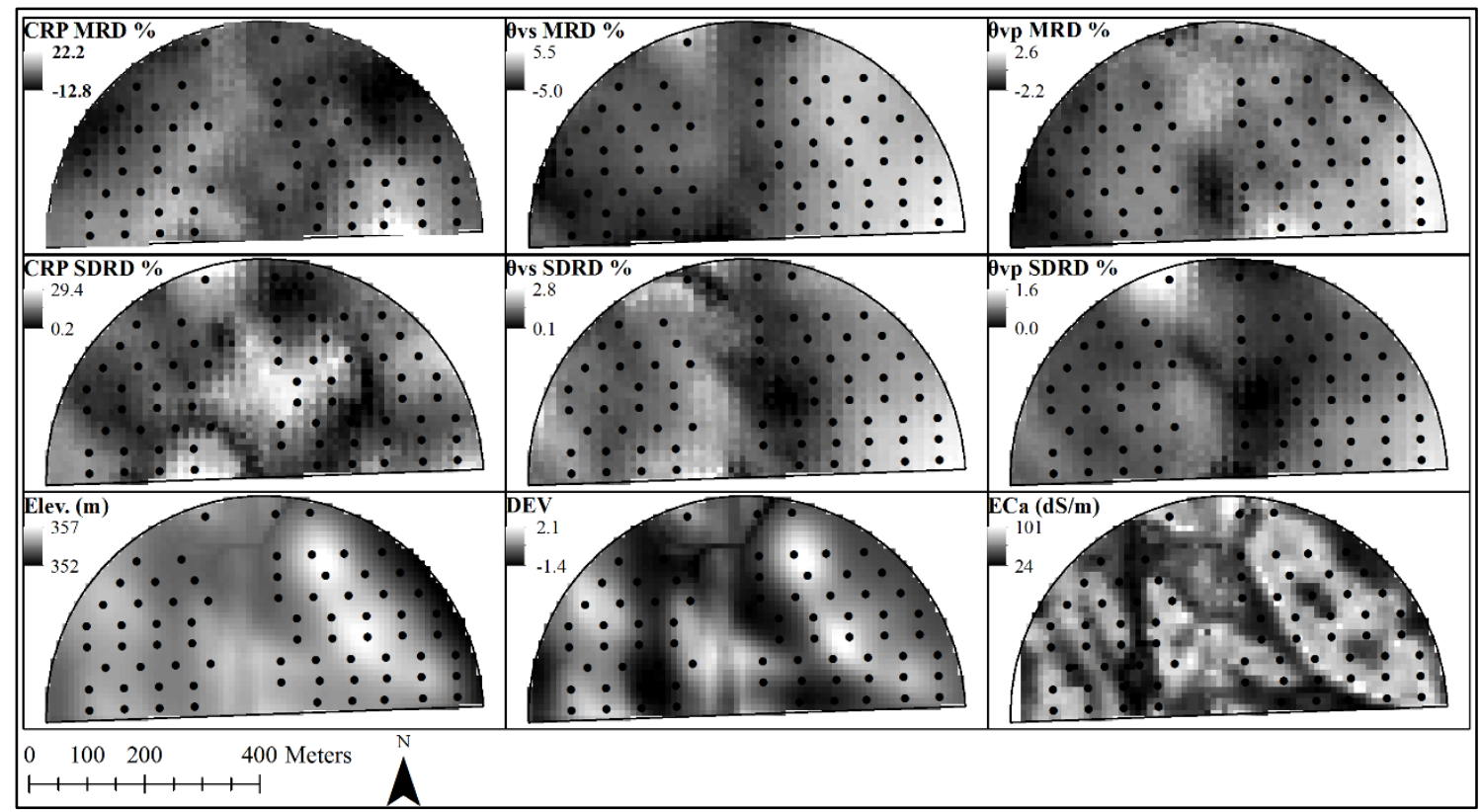

Figure 6. Maps of mean relative difference (MRD), standard deviation of relative difference (SDRD), for the cosmic ray probe (CRP) surveys and interpolated neutron probe shallow and profile average volumetric water content $\left(\theta_{\mathrm{vs}}\right.$ and $\theta_{\mathrm{vp}}$, respectively) with other spatial variables. MRD and SRD were computed for Jun $30-\mathrm{Jul} 1$, Jul $7-8$, and Jul 21 - 22, 2015, and May 6, 2016. Elev. is elevation and is m above mean sea level; DEV is deviation from mean elevation (De Reu et al., 2013); and $\mathrm{EC}_{\mathrm{a}}$ is apparent electrical conductivity. 